\title{
Preventing Glass Alteration in Museum Objects using ALD Deposited Amorphous Alumina Coatings
}

\section{Miriam E Hiebert}

University of Maryland Department of Materials Science and Engineering

\section{Jamie Weaver}

NIST Materials Measurement Laboratory

Thomas Lam

Smithsonian Institution Museum Conservation Institute

Nicole Little

Smithsonian Institution Museum Conservation Institute

\section{Ethan Hyde}

University of Maryland, Department of Materials Science and Engineering

\section{Edward P Vicenzi}

Smithsonian Institution Museum Conservation Institute

\section{Raymond J. Phaneuf ( $\triangle$ phaneuf@umd.edu )}

University of Maryland Department of Materials Science and Engineering https://orcid.org/0000-00021797-2856

\section{Research article}

Keywords: Glass, glass alteration, atomic layer deposition, ALD, amorphous alumina, glass disease

Posted Date: September 9th, 2020

DOI: https://doi.org/10.21203/rs.3.rs-71473/v1

License: (c) (i) This work is licensed under a Creative Commons Attribution 4.0 International License.

Read Full License 
Preventing Glass Alteration in Museum Objects using ALD Deposited Amorphous Alumina Coatings

4 Miriam E. Hiebert ${ }^{1,2}$, Jamie Weaver ${ }^{3,2 \S}$, Thomas Lam ${ }^{2}$, Nicole Little ${ }^{2}$, Ethan Hyde ${ }^{1}$, Edward P. 5 Vicenzi ${ }^{2,3 \S}$, Raymond J. Phaneuf ${ }^{1, *}$

${ }^{1}$ Department of Materials Science and Engineering, University of Maryland, College Park, $8 \quad$ Maryland 20742

$9 \quad{ }^{2}$ Smithsonian Institution, Museum Conservation Institute, 4210 Silver Hill Road

10 Suitland, Maryland 20746

$11{ }^{3}$ National Institute of Standards and Technology, Materials Measurement Laboratory, 100

12 Bureau Dr, Gaithersburg, Maryland 20899

13

$14 \S$ Second affiliations are via nonfunded, guest research appointments at listed institutions.

15 * Corresponding author; phaneuf@umd.edu 


\section{$17 \underline{\text { Abstract }}$}

The chemistry and kinetics of glass alteration have been topics of considerable study and

19 debate over the past several decades. While work is still progressing in understanding the

20 mechanisms by which glass degrades, what has not been as well studied are methods of slowing

21 or preventing the alteration of glass surfaces and objects. This is of significant interest to the

22 heritage science community, where the breakdown of historic glass or glass art objects is

23 proceeding, with few viable options available to museum conservators to mitigate its effects.

24 Experimental measurements using atomic layer deposited (ALD) aluminum oxide coatings on a

25 model silicate glass show a significant reduction of the rate of glass alteration.

\section{$26 \underline{\text { Keywords }}$}

27 Glass, glass alteration, atomic layer deposition, ALD, amorphous alumina, glass disease

\section{Introduction}

Silicate glass is a thermodynamically metastable phase that over time undergoes chemical

32 and physical alterations to attain a more stable state $[1,2,3]$. Though the process of glass

33 alteration can be slow relative to a human timescale, it presents a complex and pervasive

34 problem in applications where the longevity of the glass structure is important $[4,5]$. These

35 applications range from the storage of nuclear waste [6,7], to maintaining the efficiency of solar

36 cell components [8], to the focus of this work: the preservation of historic glass objects in

37 cultural heritage collections. 
Alteration of silica-based glass is a complex process, the kinetics and chemistry of which

39 are dependent on the composition of the glass as well as on the environmental conditions (e.g.

$40 \mathrm{pH}$, temperature, altering solution composition) in which it has aged [4]. The initial alteration of

41 a glass most often takes place via ion-exchange between positively charged water species $\left(\mathrm{H}^{+}\right.$

42 and $\mathrm{H}_{3} \mathrm{O}^{+}$) and the cationic glass network modifiers (e.g. alkali and alkaline earths) [9]. This is

43 usually accompanied by the hydrolysis of the

44 glass network, which can result in the release of

45 other glass forming species into solution (e.g.

$46 \mathrm{Si}, \mathrm{Al}$, and $\mathrm{Fe})$. As alteration proceeds other

47 processes may also occur. For example, a

48 change in solution chemistry may cause the

49 formation of crystalline secondary alteration

50 products, which may in turn change the rate of

51 alteration [7]. Hydrolysis and ion exchange can

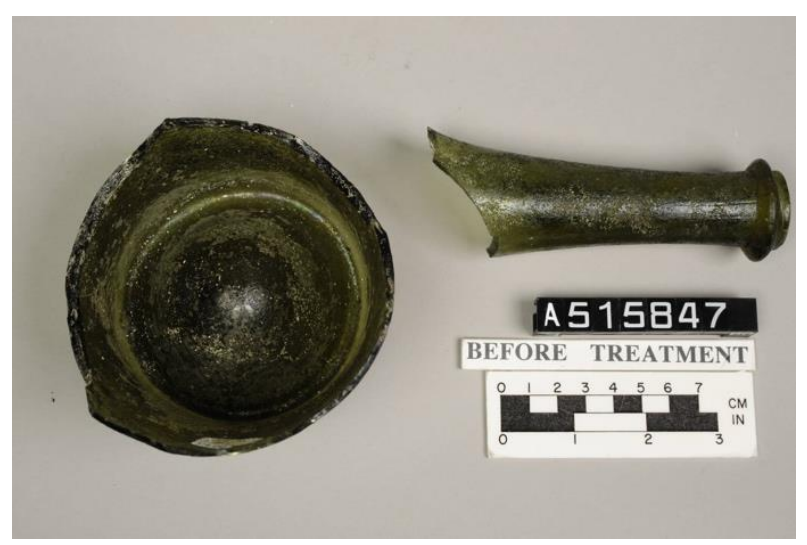

Figure 1: Fragments of an altered $18^{\text {th }}$ century French glass wine bottle in the collection of the Smithsonian Institution's National Museum of Natural History. Excavated by R.K. Harris at Los Adaes in Natchitoches Parish, Louisiana. Photo taken by Anthropology Conservation Lab, Smithsonian Institution.

52 result in the formation of a hydrated silicate gel layer on the surface of the glass, the

53 swelling/contraction of which produce stress across the interface between the alteration layer and

54 the glass driving crack nucleation [10, 11]. Micro-crack networks in the gel layer and ultimately,

55 the formation of salt precipitates on the surface, may result in a hazed and crusted appearance

56 most often associated with degraded glass as shown in Figure 1 [7]. In museum studies and

57 historical materials conservation literature this phenomenon is often referred to as "glass disease"

58 [5]. 
For the past two decades, one of the most widely accepted models for glass degradation

60 [12] has been based upon the formation of three distinct layers, with a reaction zone (layer 2)

61 forming between underlying bulk glass (layer 3) and a hydrated silicon-oxygen-rich gel altered

62 zone (layer 1) on the surface, illustrated schematically in Figure 2. Following this process, it is

63 often hypothesized that glass alteration is a diffusion-limited process in which the rate of

64 degradation is determined by the interdiffusion of ambient protons into, and cations out of, the

65 bulk glass to form a gel (alteration) layer and a reaction zone [7]. However, recent work

66 conducted by Hellman, et al. [13] suggests that the kinetics of glass degradation could also be

67 reaction-limited, involving coupled glass dissolution and selective re-precipitation of the

68 secondary, hydrated silicate

69 gel layer.

Regardless of which

71 kinetic mechanism limits

72 glass alteration rates, the

73 enabling factor is water or

74 other H-bearing molecular

75 species coming into contact

76 with the glass surface.

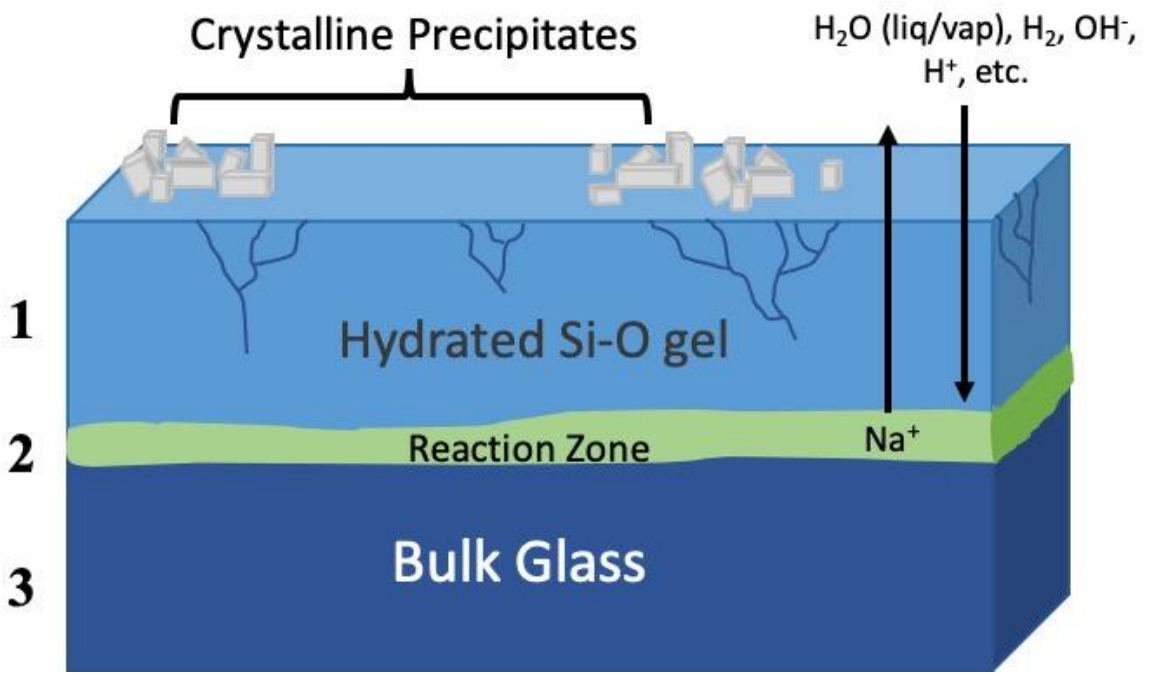

Figure 2: Schematic illustration depicting the three distinct layers of an altered glass surface, assuming a diffusion limited process (adapted from

77 Therefore, the most effective way to slow glass alteration is to isolate the underlying glass from

78 the ambient reservoir of such species. Currently, very few options exist to markedly slow or

79 prevent glass alteration from occurring. These options include the application of sol-gel silica

80 coatings, which ultimately suffer from the same hydration driven swelling as the glass [14], the

81 application of graphene, which has shown to be effective but is not feasible for application over 
82 large areas [15], and the use of dry cases filled with nitrogen gas in museums, which is effective

83 but expensive to purchase and maintain; this last approach is limited to relatively small, high

84 value objects [16]. The current paper examines the use of atomic layer deposited (ALD)

85 amorphous metal oxide coatings as diffusion barriers for reducing the rate at which water or

86 other H-bearing molecular species come into contact with the surface of glass objects, thereby

87 slowing alteration of these surfaces.

88 The scope of this paper is on the efficacy of ALD coatings for the mitigation of glass

89 alteration. However, in addition to efficacy, there are other factors that are important to

90 understand prior to the use of new methods as conservation treatments in museums which will

91 not be discussed here. These factors include the effect of the applied coatings on the appearance

92 of the object, and the reversibility of the treatment. Ongoing work to characterize degree of the

93 apparent color change imparted by the applied coatings as well as the relative rates of etching for

$94 \mathrm{Al}_{2} \mathrm{O}_{3}$ ALD from these glass surfaces will be reported elsewhere.

\section{Methods/Experimental}

96 Glass Samples:

97 Soda lime float glass, the glass type most typically used in modern windows, is silica

98 based with $\mathrm{Na}_{2} \mathrm{O}$ as the primary flux and $\mathrm{Ca}(\mathrm{OH})_{2}$ as a stabilizer. Samples of this type of glass

99 (from a window from a commercial manufacturer (Guardian Glass)) were chosen for this study.

100 The glass has a composition with mass fractions of approximately $0.75 \mathrm{~kg} / \mathrm{kg} \mathrm{SiO}$ and 0.10

$101 \mathrm{~kg} / \mathrm{kg} \mathrm{Na}_{2} \mathrm{O}$. Other major, minor and trace additives listed in Table 1. 


\section{Light Microscopy}

104 Light optical microscopy images were collected using a HiROX KH-8700 3D digital

105 microscope with an embedded proprietary operating system and software package. Visible light

106 microscopy was used to obtain reflected bright-field montages, each covering an area $\approx 1 \mathrm{~cm} \times 1$

$107 \mathrm{~cm}$ of the sample surfaces. These images were then processed using a manual thresholding

108 feature in the ImageJ open source software package [17] to binarize the image and estimate the

109 percent area that remained coated with $\mathrm{ALD} \mathrm{Al}_{2} \mathrm{O}_{3}$ or $\mathrm{TiO}_{2}$ after a period of accelerated aging.

110 This process was performed for images obtained from both of the large faces of each glass

111 sample (approximately $1 \mathrm{~cm}$ by $1 \mathrm{~cm}$ ) yielding an estimate of the percentage of the surface left

112 bare after aging.

\section{Scanning Electron Microscopy and Microanalysis}

114 Electron microscopy images of glass surfaces and X-ray microanalyses to determine the

115 composition of the glass were obtained using a Hitachi S3700N scanning electron microscope

116 (SEM) equipped and a Bruker X-Flash 6|60 energy dispersive spectrometer (EDS). A beam

117 energy of $7 \mathrm{keV}$ and a constant probe current of $2.00 \mathrm{nA} \pm 0.02 \mathrm{nA}$ was used for these

118 measurements. For calibrandt-based quantified samples, both the calibrandts and samples were

119 carbon coated with a layer thickness $\approx 25 \mathrm{~nm}$ using a Cressington 108 Auto/SE sputter coater. A

120 well characterized calibrandt-based quantification method using a Phi-Rho-Z matrix correction

121 routine [18] implemented in the Bruker Esprit V2.2 software package was used to determine

122 glass compositions (see SI Table 1 for a listing of primary standards). Corning reference glasses

123 A and B were used as secondary calibrandts (samples of known composition which are measured

124 prior to the analysis of an unknown sample in order to verify that the compositional 
measurements and calculations being used produce accurate results) and the percent deviations

126 from the expected values were found to be less than $7 \%$ for the oxides of all major elements (SI

127 Table 2; [19]).

128 To mitigate potential effects of glass inhomogeneity, multiple samples taken from

129 random locations on a large glass pane were used in each experiment and the results were

130 averaged. Modern float glass manufacturing processes involve exposure to liquid tin on one side

131 of the window which allows a trace amount of tin to diffuse into that face of the glass [20]. To

132 account for this, the composition was measured on both faces of the glass window.

133 Table 1: Quantitative EDS compositional data for an uncoated window glass. The mean of 15 measurements from 134 both sides of the float glass is expressed as oxide mass fraction ( $\mathrm{kg} / \mathrm{kg}$ ) multiplied by $10^{2}$ for readability. Up is the 135 liquid tin-exposed side and 'down' is the unexposed side. Uncertainty is reported to one standard deviation of the 136 population statistics $(n=15$, where $n$ is the sample size, per side).

137

ALD Coating:

\begin{tabular}{ccc}
\hline Oxide & $\begin{array}{c}\text { Glass } \\
(\mathrm{kg} / \mathrm{kg} \mathrm{x} \mathrm{10})\end{array}$ & $\begin{array}{c}\text { Glass } \\
(\mathrm{kg} / \mathrm{kg} \mathrm{x} \mathrm{10})\end{array}$ \\
Face: & up & down \\
\hline $\mathrm{SiO}_{2}$ & $73.56 \pm 0.90$ & $75.60 \pm 0.76$ \\
$\mathrm{TiO}_{2}$ & $0.03 \pm 0.077$ & $0.08 \pm 0.06$ \\
$\mathrm{Al}_{2} \mathrm{O}$ & $0.81 \pm 0.10$ & $0.791 \pm 0.026$ \\
$\mathrm{Fe}_{2} \mathrm{O}_{3}$ & $0.11 \pm 0.05$ & $0.07 \pm 0.03$ \\
$\mathrm{MgO}$ & $3.88 \pm 0.14$ & $3.825 \pm 0.09$ \\
$\mathrm{CaO}$ & $8.12 \pm 0.28$ & $8.11 \pm 0.12$ \\
$\mathrm{Na}_{2} \mathrm{O}$ & $12.19 \pm 0.57$ & $12.12 \pm 0.29$ \\
$\mathrm{~K}_{2} \mathrm{O}$ & $0.33 \pm 0.02$ & $0.35 \pm 0.03$ \\
$\mathrm{SO}_{3}$ & $0.08 \pm 0.03$ & $0.12 \pm 0.02$ \\
$\mathrm{SnO}_{2}$ & $0.84 \pm 0.53$ & $\mathrm{n} / \mathrm{a}$ \\
$\mathrm{Total}$ & $99.76 \pm 1.51$ & $101.06 \pm 0.38$ \\
\hline
\end{tabular}

ALD coatings were deposited on the glass samples using a commercial (Beneq TFS 500)

140 ALD reactor located in the Nano Fabrication Lab at the University of Maryland. This study

141 focused primarily on $\mathrm{Al}_{2} \mathrm{O}_{3}$ ALD coatings, which have a uniform, near unity transmission across 
142 the visible light spectrum.

143 Therefore, thin alumina

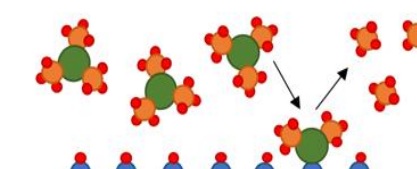

144 coatings (optical path

145 length 2 nd $<<$ visible

146 light wavelength $\lambda$ ) are

147 not easily detected by

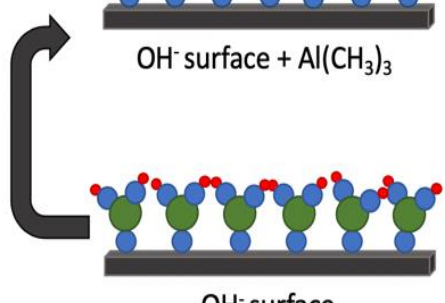

$\mathrm{OH}^{-}$surface

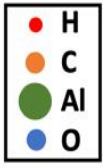

$\mathrm{CH}_{3}$ surface

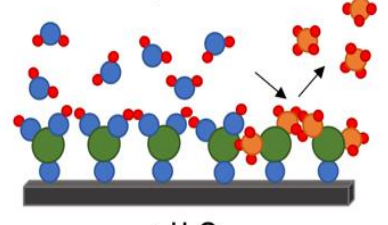

$+\mathrm{H}_{2} \mathrm{O}$

148 human vision and are

Figure 3: Schematic of the chemical steps in the idealized depostion of $\mathrm{Al}_{2} \mathrm{O}_{3} \mathrm{ALD}$.

149 appropriate for museum applications [21]; for thicker films, optical interference between

150 reflections at the surface and interface with the substrate can lead to visible color shifts [22]. In

151 spite of a nonuniform optical absorption across the visible spectrum, $\mathrm{TiO}_{2} \mathrm{ALD}$ coatings, which

152 cause the glass to appear blue, were also examined in this work owing to a previous report of the

153 relative lack of durability of alumina $\mathrm{ALD}$ films in water [23]. The $\mathrm{Al}_{2} \mathrm{O}_{3} \mathrm{ALD}$ coating process

154 used trimethylaluminum (TMA) and water as precursor gasses while $\mathrm{TiO}_{2} \mathrm{ALD}$ used

155 tetrakis(dimethylamido)titanium (TDMAT) and water as precursors. Figure 3 depicts a

156 schematic of the idealized deposition process for $\mathrm{Al}_{2} \mathrm{O}_{3} \mathrm{ALD}$.

Exposure and purge times for the precursor gases were determined empirically based on

158 perceived color uniformity across a $\mathrm{Si}$ wafer that was included in the reactor chamber during

159 each deposition experiment; gradients in the local pressure within the reactor lead to thickness

160 variations if the individual reactions do not reach saturation The pulse/purge times suggested by

161 the ALD reactor manufacturer were found to be insufficient for coating the silicon wafers, and

162 presumably the silicate glass samples uniformly. Therefore, the suggested precursor exposure

163 and purge times were quadrupled, resulting in a uniform visual appearance; these resulting times

164 are listed in Table 2. All depositions discussed here were performed at $150{ }^{\circ} \mathrm{C}$. 
Table 2: Precursor exposure and purge times used for the deposition of $\mathrm{Al}_{2} \mathrm{O}_{3}$ and $\mathrm{TiO}_{2} \mathrm{ALD}$ films onto commercial 166 float glass.

\begin{tabular}{|c|c|c|}
\hline ALD Deposition Parameter & $\begin{array}{c}\mathrm{Al}_{2} \mathrm{O}_{3} \\
\text { trimethylaluminum } \\
\text { (TMA) }\end{array}$ & $\begin{array}{c}\mathrm{TiO}_{2} \\
\text { tetrakis(dimethylamido)titanium } \\
\text { (TDMAT) }\end{array}$ \\
\hline Exposure time (s) & 2 & 1 \\
\hline Purge $_{1}$ time (s) & 2 & 0.5 \\
\hline $\mathrm{H}_{2} \mathrm{O}$ exposure time (s) & 2 & 1 \\
\hline Purge $_{2}$ time (s) & 2 & 0.5 \\
\hline
\end{tabular}

167

A custom support was developed for coating these samples, consisting of $1 \mathrm{~mm}$ diameter

169 glass spheres (Sigma Aldrich) that were low-temperature-fused to a thin glass sheet. This

170 allowed for the elevation of the samples, aiding exposure of the bottom surfaces of the substrate

171 to the ALD precursor gases. Samples were flipped over halfway through each coating process to

172 expose the contact points that the sample made with the support and to promote complete sample

173 coating.

174 Coating Thickness

175 Subsequent to sample coating, the average thickness of the applied ALD coatings versus

176 the number of deposition cycles was determined by spectroscopic ellipsometry. The ellipsometry

177 was performed on a Woollam M2000 spectroscopic ellipsometer. Both a tungsten filament and a

178 deuterium bulb light source were used to cover a wavelength range of $190 \mathrm{~nm}-1800 \mathrm{~nm}$. These

179 analyses were performed with the instrument in horizontal mode due to the weight of the

180 samples. The proprietary Woollam software package CompleteEase was used to build sample

181 models, including optical constants and film and substrate parameterization, and to fit the

182 resulting data. Results are reported in Table 3.

183 The $\mathrm{Al}$ or Ti signals obtained via SEM-based $\mu \mathrm{XRF}$ were measured for increasing

184 numbers of cycles of ALD deposition. The relationship between the $\mu$ XRF output and 
185 ellipsometry thicknesses was found to be highly linearly correlated as the number of ALD

186 deposition cycles is increased beyond an initial transient (discussed below). Taking advantage of

187 this correlation, the $\mu \mathrm{XRF}$ signal was used to estimate the ALD coating thicknesses. The $\mu \mathrm{XRF}$

188 analysis was performed under high vacuum in the SEM using a Bruker XTrace $\mu$ XRF with a 50

$189 \mathrm{kV}$ polychromatic $\mathrm{Rh}$ source and an X-ray optic that produced a $33 \mu \mathrm{m}$ (measured at $\mathrm{Cu} \mathrm{K} \alpha$ )

190 elliptical spot with an approximate area between $900 \mu \mathrm{m}^{2}$ and $1000 \mu \mathrm{m}^{2}$. X-ray spectra were

191 collected for 60 live seconds. Using Bruker Esprit v2.1, the resulting X-ray scatter was

192 background fit using a spline interpolation of non-peak channels and peaks were fitted using

193 Gaussians with overlapping X-ray lines deconvolved to yield the net counts of $\mathrm{Al}$ or Ti that

194 represent the sum signal resulting from the glass substrate plus the ALD thin film [24]. The

195 results for both ellipsometry and $\mu \mathrm{XRF}$ analysis are reported in Table 3.

\section{Surface Topography}

198 The surface topography of the ALD coated and uncoated samples was characterized 199 using a Digital Instruments Dimension 3100 atomic force microscope (AFM) in tapping mode 200 with a $300 \mathrm{kHz}$ resonant frequency silicon cantilever (Nanosensors) with a nominal $10 \mathrm{~nm}$ 201 terminal tip radius; maps were recorded for the silicate glass samples as a function of the number 202 of ALD deposition cycles. Glass samples were cleaned using sonication in a series of stock grade 203 solvents (isopropanol, acetone, methanol, deionizied (DI) water) prior to analysis. The RMS

204 (root-mean-square average of the deviations in profile height from the mean) roughness was 205 determined, based on scans of $5 \mu \mathrm{m} \times 5 \mu \mathrm{m}$ lateral dimensions across these surfaces, using the 206 Bruker NanoScope (R) IIIa software package, version 5.33R1sr1. 
209 As glass alteration under ambient conditions is a slow process on laboratory time scales

210 even in the absence of barrier coatings, a method of artificial accelerated aging, involving

211 immersion of glass in water at an elevated temperature, was employed. An ASTM standard

212 method was adapted for evaluating product stability of industrially produced windows (ASTM-

213 PCT C1285) [25]. The original method calls for using a monolith of glass and sealing it in a

214 polyflouroalkoxy polytetrafluoroethylene (PFA PTFE)-fluorocarbon vessel with a known

215 amount of ultrapure water at elevated temperature for a given amount of time. In this study small

216 blocks of glass, each with mass of $1.00 \mathrm{~g} \pm 0.05 \mathrm{~g}$ (as determined by weighing each sample and

217 selecting only those with weights measured within this range), and dimensions of $\approx 0.5 \mathrm{~cm}$ in

218 thickness, and $\approx 1.0 \mathrm{~cm}$ by $1.0 \mathrm{~cm}$ in length and width were cut. Glass samples were cleaned

219 using sonication in a series of stock grade solvents (isopropanol, acetone, methanol, DI water),

220 and then placed in individual TFE vessels (Savillex) along with $10.00 \mathrm{~mL} \pm 0.04 \mathrm{~mL}$ of ultra-

221 high purity DI water, with an initial measured resistivity of approximately $18 \mathrm{M} \Omega$-cm (Millipore

222 Milli-Q Integral 3 water purification system). The vessels were then placed in an oven (Quincy

223 Lab Inc., 10GC Gravity Convection Oven) held at $90{ }^{\circ} \mathrm{C} \pm 5{ }^{\circ} \mathrm{C}$, for prescribed lengths of time.

224 At the end of each accelerated aging experiment the glass was removed from its vial, allowed to

225 dry in atmosphere, and then stored for subsequent analysis. Samples of glass, coated via ALD

226 with a range of thicknesses of either $\mathrm{Al}_{2} \mathrm{O}_{3}$ or $\mathrm{TiO}_{2}$ oxides, were subjected to the same method of

227 accelerated aging described above for aging uncoated glass. To account for variation in the

228 samples and the aging method, generally multiples of six samples were aged simultaneously (an

229 exception was for an aging experiment of $336 \mathrm{~h} \pm 4 \mathrm{~h}(\approx 14$ days $)$ of aging uncoated glass, where

230 the number of samples was 12) in each experiment; the results for the multiple samples were 
231 averaged. For uncoated glass samples the immersion time was varied from (24 to 336$) \mathrm{h} \pm 4 \mathrm{~h}$.

232 For the majority of the aging experiments on ALD coated samples an immersion time of $336 \mathrm{~h} \pm$

$2334 \mathrm{~h}$ was used; an exception to this was one experiment where glass coated with 1000 cycles of

$234 \mathrm{Al}_{2} \mathrm{O}_{3} \mathrm{ALD}$ was aged for $168 \mathrm{~h} \pm 4 \mathrm{~h}(\approx 7$ days $)$.

236 ICP-MS Analyses:

237 Subsequent to aging, the aqueous solution from which a sample had been removed was 238 analyzed for the concentration of $\mathrm{Si}$ and $\mathrm{Na}$ leached from the glass. This was done using a GBC 239 Optimass 9500 Time-of-Flight Inductively Coupled Plasma-Mass Spectrometer (ICP-MS). For 240 this analysis, $0.1 \mathrm{~g}$ aliquots of the sample water were diluted to a total weight of $50.0 \mathrm{~g}$ using 18 $241 \mathrm{M} \Omega-\mathrm{cm}$ ultrapure water. An internal standard (High-Purity Standards IS-2) was added to each

242 sample in $0.2 \mathrm{~g}$ aliquots and was used to track the stability of the instrument and the accuracy of

243 the analyses over time. Calibration of the instrument was done using two different multi-element 244 standard solutions containing the elements of interest (High-Purity Standards 68 Component 245 ICP-MS Standards A and B). The dilutions, concentrations, and contents of all three standards 246 used can be found in SI Table 3. Analyses were run in sets of ten for each sample measured and 247 the relative standard deviations output by the instrument software (Optimass version 2.2) were 248 found to be on average $4.2 \%$ for $\mathrm{Na}$ and $4.1 \%$ for $\mathrm{Si}$.

249 In addition to analyzing the aqueous leachate, analyses were also performed on three 250 samples of water that had not been in contact with a glass sample but that had been subjected to 251 identical aging and storage conditions to serve as aqueous "blanks". The values measured from 252 these blank samples were averaged and the average concentrations were subtracted from the 253 values obtained from the leachate that had contained the glass samples. The resulting 
254 "background" corrected concentrations, determined for each of the multiple samples with a given 255 coating type, coating thickness, and aging time were averaged together and the resulting mean 256 values are reported in Figure 6 to one standard deviation of the population statistics.

\section{$257 \quad$ Results and Discussion}

\section{Characterizing ALD Coatings on Glass:}

While ALD on chemically uniform surfaces such as Si wafers has been relatively well

261 studied [26, 27], deposition on chemically inhomogeneous surfaces is less well understood [28,

262 29]. Characterization of the uniformity, or "conformality" of the applied coatings to the substrate

263 was needed to determine the number of ALD cycles needed to cover the surface of the glass

264 completely, and to investigate possible defects in the applied film.

\section{Coating Thickness}

266 Initial characterization of the ALD coatings included assessing the thickness of the

267 applied coatings on the glass surfaces. Table 3 and Figure 4 summarize the coating thicknesses

268 as measured by ellipsometry and the corresponding $\mu$ XRF measurement output for each ALD

269 coating and thickness studied. 
Table 3: Table listing the results of thickness values determined by ellipsometry (on both the uncoated glass sample $(\mathrm{n}=3)$ and included Si wafer $(\mathrm{n}=1))$ and the elemental signal obtained from the coated samples via $\mu$ XRF $(\mathrm{n}=5)$. Growth per cycle (GPC) is reported based upon these results. Uncertainties are reported as the square root of the measured value for the ellipsometric measurements on the Si wafer and as one standard deviations of the population statistics obtained for all other measurements reported.

\begin{tabular}{|c|c|c|c|c|c|c|}
\hline \multirow[t]{3}{*}{$\begin{array}{c}\text { Cycles } \\
\text { ALD }\end{array}$} & \multicolumn{3}{|c|}{$\begin{array}{c}\mathbf{A l}_{2} \mathbf{O}_{3} \mathbf{A L D} \\
G P C \approx 0.17 \mathrm{~nm} / \mathrm{cycle}, \approx 74 \text { counts } / \text { cycle }\end{array}$} & \multicolumn{3}{|c|}{$\begin{array}{c}\mathbf{T i O}_{2} \mathbf{A L D} \\
G P C \approx 0.06 \mathrm{~nm} / \text { cycle }, \approx 52 \text { counts } / \text { cycle }\end{array}$} \\
\hline & \multicolumn{2}{|c|}{$\begin{array}{l}\text { Thickness from } \\
\text { Ellipsometry (nm) }\end{array}$} & \multirow{2}{*}{$\begin{array}{c}\mu \mathrm{XRF} \text { Al } \mathrm{K}_{\alpha} \\
\text { (net counts) } \\
n=10\end{array}$} & \multicolumn{2}{|c|}{$\begin{array}{l}\text { Thickness from } \\
\text { Ellipsometry (nm) }\end{array}$} & \multirow{2}{*}{$\begin{array}{c}\mu \mathrm{XRF} \text { Ti } \mathrm{K}_{0} \\
\text { (net counts) } \\
n=10\end{array}$} \\
\hline & Glass & Si wafer & & Glass & Si wafer & \\
\hline $\mathbf{0}$ & 0 & 0 & $1833 \pm 543$ & 0 & 0 & $1444 \pm 38$ \\
\hline 25 & $0.7 \pm 0.8$ & $4.1 \pm 2.0$ & $3508 \pm 467$ & $\mathrm{n} / \mathrm{a}$ & $\mathrm{n} / \mathrm{a}$ & $\mathrm{n} / \mathrm{a}$ \\
\hline 50 & $2.3 \pm 1.5$ & $8.1 \pm 2.8$ & $4803 \pm 645$ & $\mathrm{n} / \mathrm{a}$ & $\mathrm{n} / \mathrm{a}$ & $\mathrm{n} / \mathrm{a}$ \\
\hline 100 & $17.9 \pm 7.9$ & $15.8 \pm 4.0$ & $8840 \pm 843$ & $5.3 \pm 0.3$ & $6.1 \pm 2.5$ & $4861 \pm 69$ \\
\hline 200 & $32.5 \pm 4.2$ & $31.0 \pm 5.5$ & $14861 \pm 1932$ & $14.1 \pm 0.0$ & $12.4 \pm 3.5$ & $11681 \pm 108$ \\
\hline 500 & $90.1 \pm 2.1$ & $99.3 \pm 9.9$ & $34949 \pm 3078$ & $39.8 \pm 5.5$ & $33.1 \pm 5.7$ & $30279 \pm 174$ \\
\hline 1000 & $172.2 \pm 2.1$ & $185.1 \pm 13.6$ & $74278 \pm 4643$ & $59.0 \pm 7.7$ & $57.1 \pm 7.5$ & $52366 \pm 228$ \\
\hline
\end{tabular}

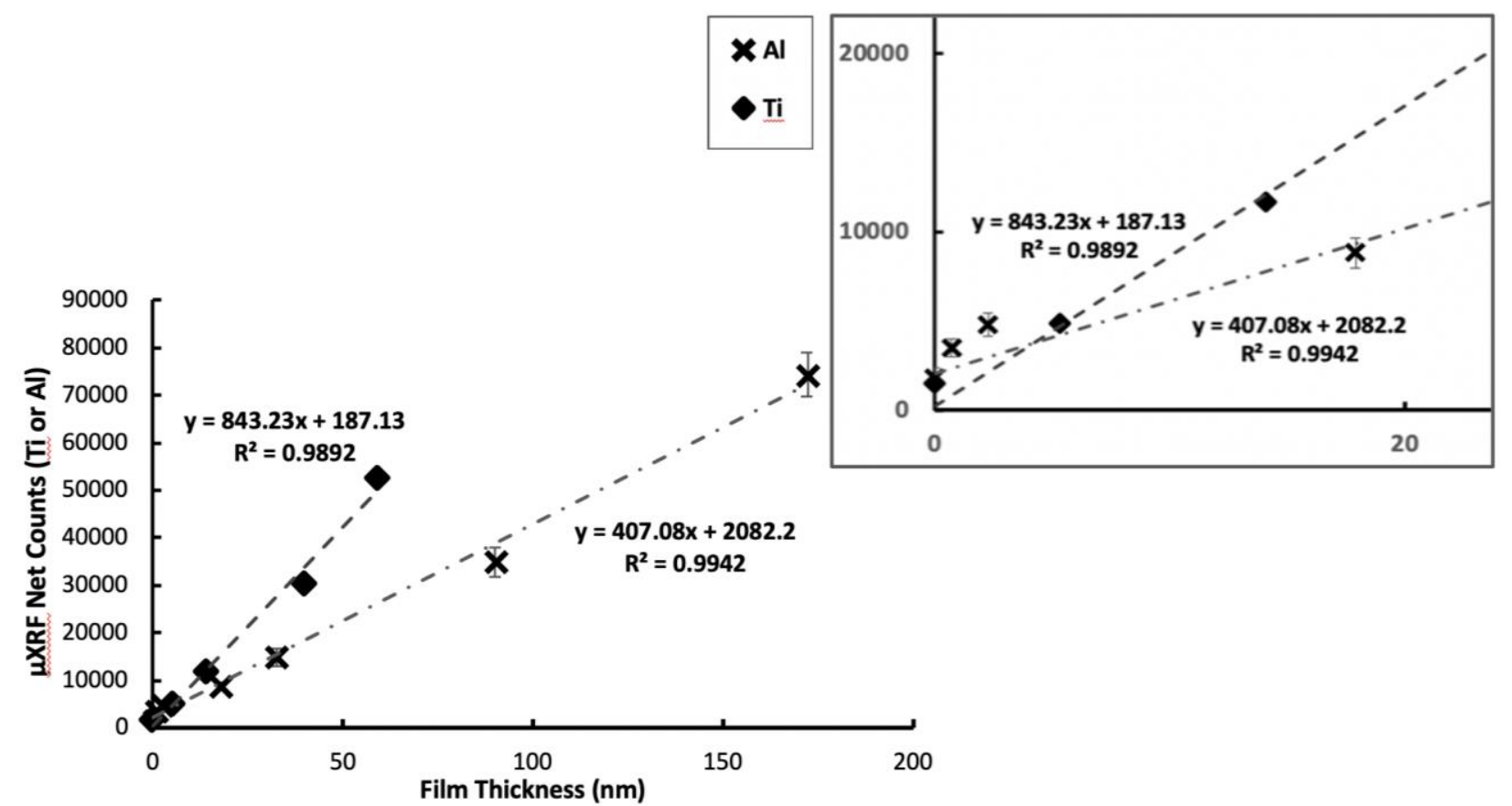

Figure 4: Graph showing relationships between coating thickness values, determined with ellipsometry, and $\mu$ XRF signals. It should be noted that the base glass itself contains small concentrations of both $\mathrm{Al}$ (1833 net counts) and Ti (1444 net counts), resulting in measured signals from both elements measured on the uncoated glass and accounting for the non-zero y-axis intercepts of the linear regression fits, shown as dashed lines. Error bars represent one standard deviation of the population statistics, however, these values, which are also reported in Table 3 , often result in error bars that are too small to be seen in this figure. 
A linear relationship between the ellipsometrically measured coating thicknesses and the

290 net counts of $\mathrm{Ti}$ and $\mathrm{Al}$ measured using $\mu \mathrm{XRF}$ can be seen in Figure 4, with regression

291 cefficients given in the figure. The non-zero y-intercepts obtained from the linear fits of the data

292 shown in this graph are consistent with the pressence of small amounts of both $\mathrm{Ti}$ and $\mathrm{Al}$ in the

293 base glass composition. The uncertainties in the linear fits were calculated for both ALD

294 coatings. For the $\mathrm{Al}_{2} \mathrm{O}_{3}$ ALD measurements, the resulting linear fit was found to have a slope of

$295406 \pm 16$ net counts/nm, and a y-intercept of $2154 \pm 1316$ net counts which is indistinguishable

296 from the measured value for net counts of $\mathrm{Al}$ in the base glass (1833 \pm 543 net counts) within the

297 statistical uncertainty. Similarly for the measurements made on the $\mathrm{TiO}_{2} \mathrm{ALD}$ coatings, the slope

298 was found to be $863 \pm 68$ net counts/nm and the $y$-intercept to be $-737 \pm 2470$ net counts, while

299 the measured value of Ti net counts in the base glass was determined to be $1444 \pm 38$.

300 The measured value of $\mathrm{Al}$ and $\mathrm{Ti}$ in the base glass were found to be within one standard

301 deviation of the $y$-intercepts obtained from the fits for each coating. However, it is interesting to

302 note that there is a systematic deviation apparent between data and the linera regression fits,

303 particularly for $\mathrm{Al}_{2} \mathrm{O}_{3}$ ALD coatings for small numbers of coating cycles, which can be

304 attributed in a deviation from layer-by-layer growth. It is apparent for these thinner coatings of

$305 \mathrm{Al}_{2} \mathrm{O}_{3} \mathrm{ALD}$, the initial thickness shows a sublinear dependence on the number of deposition

306 cycles. Following standard practice, during each of these coating experiments, a control Si wafer

307 was placed inside the ALD chamber along with the glass samples to allow for an estimation of

308 the applied coating thickness on an ideal substrate. A large discrepancy between the thicknesses

309 measured on the control wafer and the glass samples was noted for the thinnest $\mathrm{Al}_{2} \mathrm{O}_{3} \mathrm{ALD}$

310 coatings (Table 3), with the latter values initially being consistently lower. This suggests that the

311 precursors are reacting less readily with the glass surface than with the Si wafer, which may be 
312 due to locally unfavorable surface terminations on the glass. We hypothesize that island

313 nucleation and growth occur in the early stages of the formation of these coatings [26, 28].

315 Roughness of Sample Surfaces

316 A test of the hypothesis that ALD coatings nucleate and grow as multilayer islands, rather

317 than homogenously in a layer-by-layer manner, is possible via measurement of the surface

318 topography: if correct, evidence should be observable as a transient increase in the roughness of

319 the surface [30]. While it can be difficult to identify small islands of film on a rough substrate,

320 the AFM height maps indicate a transient increase in the observable surface roughness,

321 consistent with island nucleation and growth leading to some degree of coalescence (Figure 5).

322 In addition to the topographic maps, Figure 5 displays plots of the average RMS roughness

323 measured as a function of coating thickness for both $\mathrm{Al}_{2} \mathrm{O}_{3}$ and $\mathrm{TiO}_{2} \mathrm{ALD}$ coatings.

324 The peak value of the RMS surface roughness, measured for an $\mathrm{Al}_{2} \mathrm{O}_{3}$ ALD dose of 50

325 cycles $(\approx 2.3 \mathrm{~nm})$, was found to be approximately 3 times larger than that of the uncoated glass

326 and on the asymptotic value; this is qualitatively consistent with island nucleation, followed by

327 subsequent lateral, as well as vertical growth [28]. The onset of roughening and island formation

328 seemingly requires higher doses for the $\mathrm{TiO}_{2} \mathrm{ALD}$ coatings, which in turn suggests a lower

329 reactivity of TDMAT, as compared to TMA, with the silicate samples. For both the $\mathrm{Al}_{2} \mathrm{O}_{3}$ and

$330 \mathrm{TiO}_{2}$ ALD coatings the intial increase in roughness was followed by a gradual drop with

331 increased coating thickness. This behavior is consistent with growth and at least partial

332 coalescence of multilayer islands at longer deposition times [30]. 

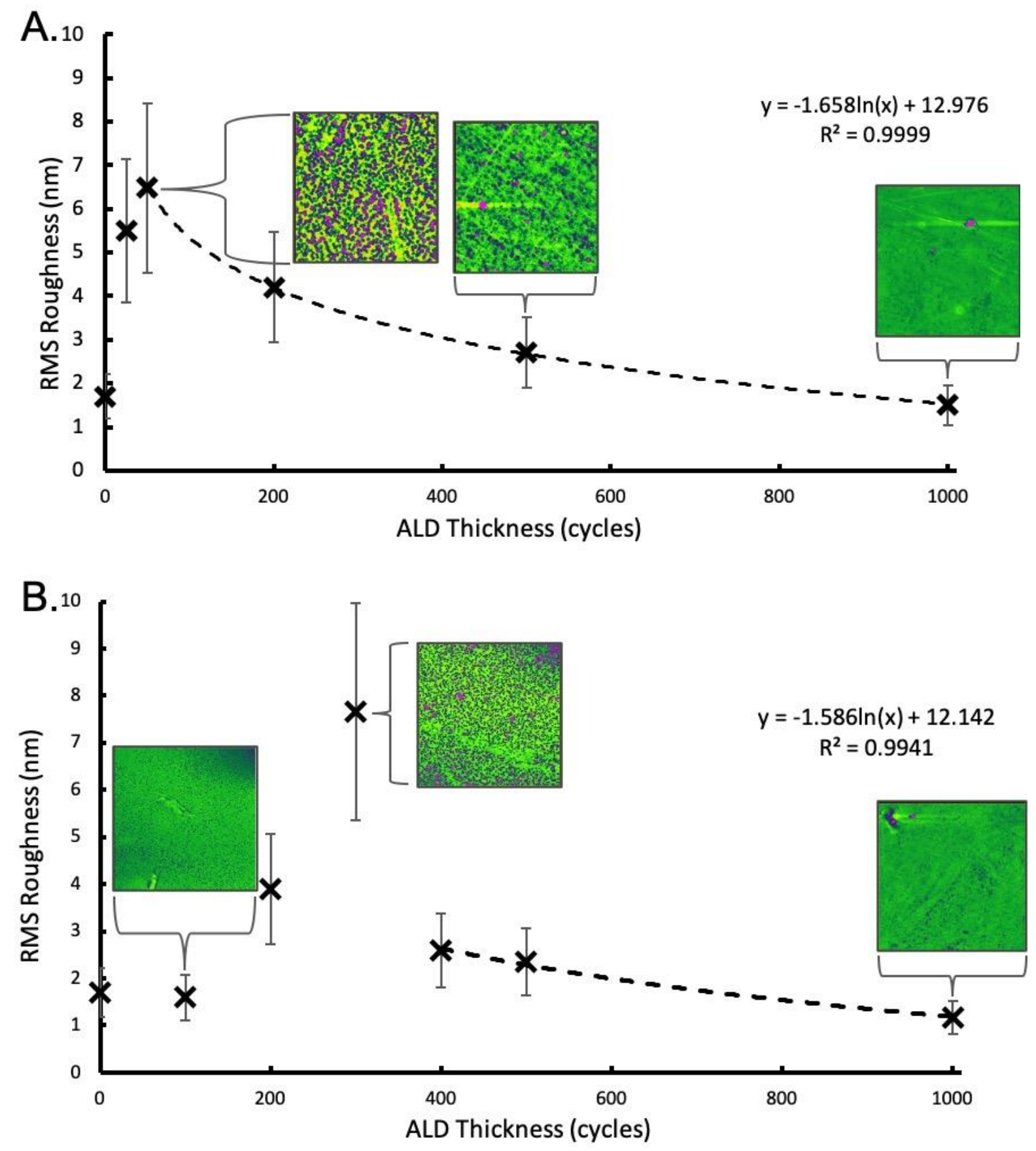

Figure 5: Plots of the average, from multiple measurements across a single surface, RMS roughness measured on samples of float glass with increasing numbers of applied deposition cycles of (A) $\mathrm{Al}_{2} \mathrm{O}_{3}$ and (B) $\mathrm{TiO}_{2} \mathrm{ALD}$ (in graph B the measurements for doses of 200 cycles, 300 cycles and 400 cycles were obtained at a later time from the rest of the measurements shown). Thumbnail images show AFM topographic maps of selected sample surfaces where the field of view is approximately $10 \mu \mathrm{m} \times 10 \mu \mathrm{m}$ area (green is shallow while purple represents peaks). It has previously been shown that for AFM measurements where the features of interest are at least double the radius of the AFM probe tip, the instrumental uncertainty is estimated to be less than $15 \%$ of the measurement [31]. Uncertainties are reported here to $30 \%$ of the measured value for $n=1$. 


\section{Uncoated Glass}

It was first necessary to characterize the alteration of float glass without any applied ALD

347 coating under the accelerated alteration method described previously in order to determine the

348 effect of an ALD coating on the glass alteration rates. The graph shown in Figure 6 presents the

349 average measured concentration of $\mathrm{Si}$ and $\mathrm{Na}$, that presumably had leached from the uncoated

350 glass, as a function of aging time. The concentrations of these species are used as a metric of

351 glass alteration as their increasing concentration in the leachate should scales with their depletion

352 in the glass matrix [32]. As can be seen from these results, an initial and rapid alteration in the

353 first three days was followed by a plateau in alteration as aging time increases. This is consistent

354 with previously reported glass alteration studies [6, 7].

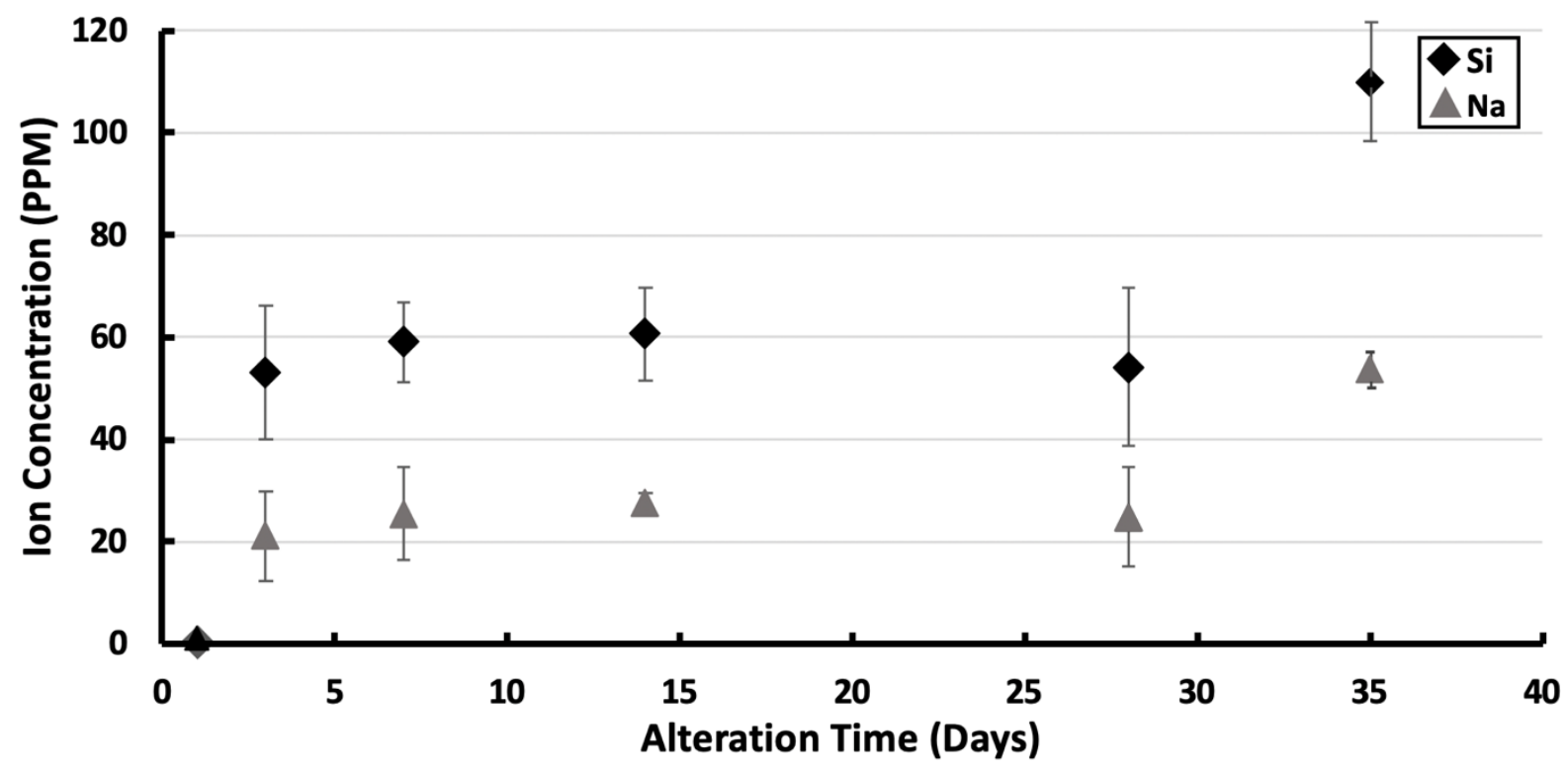

Figure 6: Solution-ICP-MS data showing average concentrations measured for Si and Na present in the water used in accelerated aging of uncoated glass samples after increasing accelerated aging time $(n=6$; except for 14 days aging where $n=12$ ). Uncertainties are shown to one standard deviation of the population statistics. 
Solution-ICP-MS analyses were performed on the aqueous solutions used in the

358 accelerated aging tests of the ALD coated glass samples. The average Si and Na concentrations

359 measured after 14 days of accelerated aging in each experiment are shown in Figure 7. While

360 concentrations of $\mathrm{Ti}$ were not measured in these samples due to instrumental constraints, $\mathrm{Al}$

361 concentrations were recorded and found to be negligible $(\cong 0)$. From the Na and Si data it is

362 observed that $\mathrm{Al}_{2} \mathrm{O}_{3} \mathrm{ALD}$ coatings that result from $\approx 50$ growth cycles, corresponding to $\approx 2.3$

363 nm thick films, show a significant drop in the amount of $\mathrm{Na}$ and $\mathrm{Si}$ lost from the glass. This

364 suggests that thin coatings of amorphous $\mathrm{Al}_{2} \mathrm{O}_{3}$ films on glass surfaces can profoundly slow the

365 rate of glass alteration.

366 An alternative interpretation of the decrease observed in this data is that dissolved species

367 are being taken up into newly formed solid phases prior to the leachate measurement. This

368 phenomenon has been reported previously for other silicate-based glasses and may be the result

369 of excess $\mathrm{Al}$ in the alteration environment [33]. Such an interpretation however would not

370 obviously be consistent with the supposition that the increasing concentration of $\mathrm{Na}$ and $\mathrm{Si}$ in the

371 leachate should scale with their depletion in the glass matrix. Additional experiments are

372 underway to allow us to distinguish between these interpretations.

373 The results obtained from analysis of the water used in aging $\mathrm{Al}_{2} \mathrm{O}_{3} \mathrm{ALD}$ coated samples

374 contrast sharply with the results obtained from analysis of the water used in aging $\mathrm{TiO}_{2} \mathrm{ALD}$

375 coated samples as shown in Figure 6. No statistically significant decreases were observed in the

376 either the $\mathrm{Si}$ or Na concentrations, measured from $\mathrm{TiO}_{2} \mathrm{ALD}$ coated samples (Figure 6A), as 

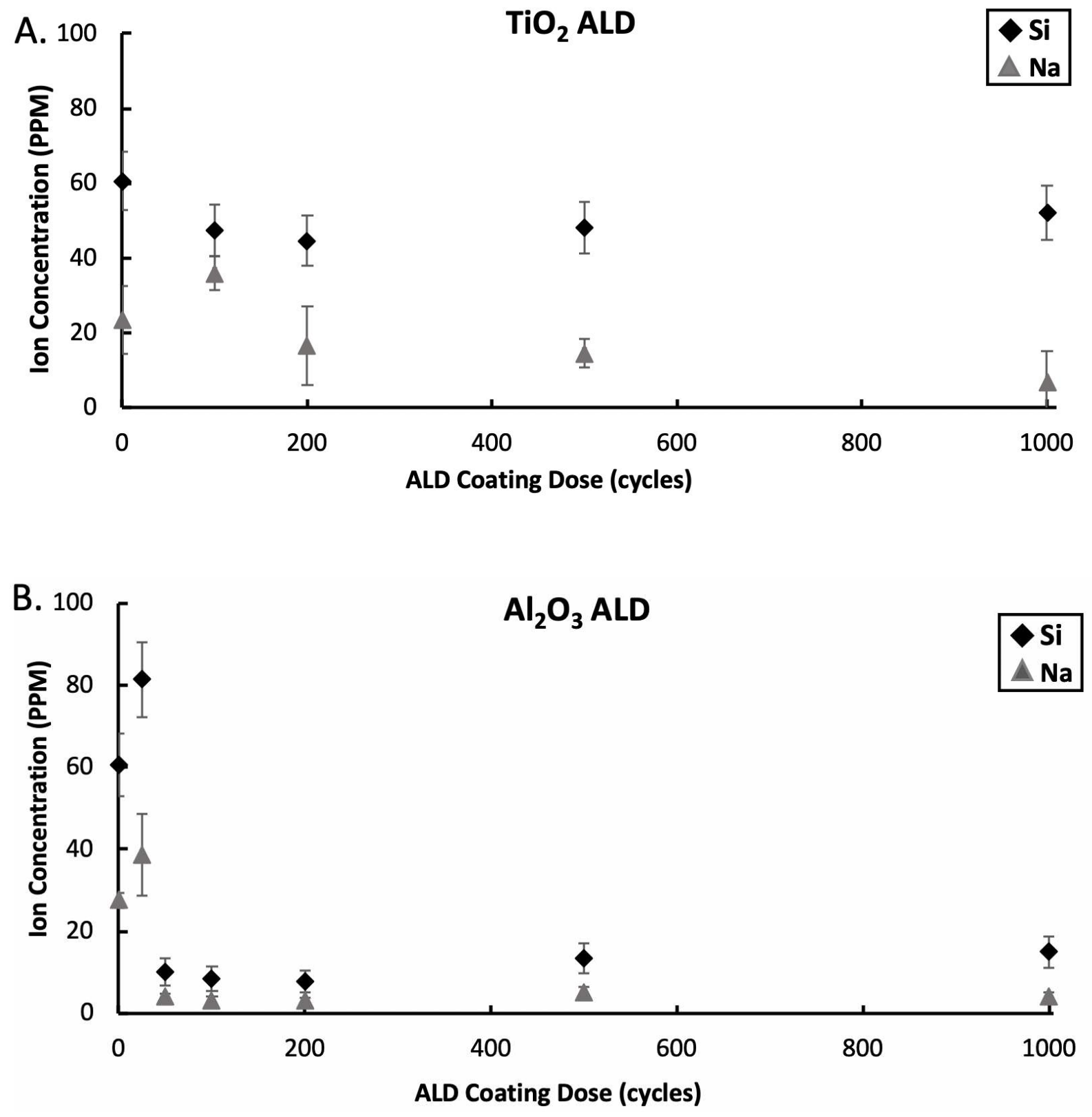

Figure 7: $\mathrm{Si}$ and $\mathrm{Na}$ ion concentration data obtained from the water from the 14 days $+/-4$ hours of accelerated aging of samples of float glass that had been coated with increasing numbers of deposition cycles of (A) $\mathrm{TiO}_{2}$ ALD and (B) $\mathrm{Al}_{2} \mathrm{O}_{3}$ ALD. Points plotted at zero cycles show data obtained from glass samples without any applied coatings (also shown in Figure 6). Multiple samples were aged $(n=6)$ for each coating and relative thickness reported. Uncertainties reported to one standard devation of the population statistics.

The ICP-MS data indicates that while there is a significant decrease in Si and Na loss for

$382 \mathrm{Al}_{2} \mathrm{O}_{3} \mathrm{ALD}$ coated glass samples (Figure 6B), the loss values remain measurable even for the 
383 thickest films investigated. However, even defect-free films allow interdiffusion of $\mathrm{Na}$ and $\mathrm{Si}$

384 under ambient conditions giving rise to finite loss but this should fall off with a characteristic

385 thickness dependence not observed here [34]. Indeed, the bulk of the loss of Na and Si measured

386 for the thickest films is likely attributable to the presence of uncoated areas on the glass as shown

387 in Figure 8 and is discussed in the next section.

389 ALD Coatings After Aging:

391 Appearance

392 After accelerated aging for 14 days, the coated glass samples were removed from the aqueous 393 solutions and visually inspected. It was immediately apparent that significant coating loss had 394 occurred during immersion in hot water. The surface of the samples appeared rough and pitted, 395 and with greater scrutiny using various microscopic methods (see Figure 8), it was apparent that 396 large areas of localized coating were lost during alteration. We postulate that these bare areas 397 may result from the expansion of smaller defects in the ALD films (discussed below), which 398 allow local alteration of the underlying glass; if so, expansion of the altered regions due to 399 hydration could cause the coating on the surrounding surface to flake off. Such bare areas were 400 observed to various degrees on all samples after accelerated aging treatment. Similar behavior 401 has been observed previously in other thin film coatings exposed to ambient humidity [35, 36]. 402 
A.

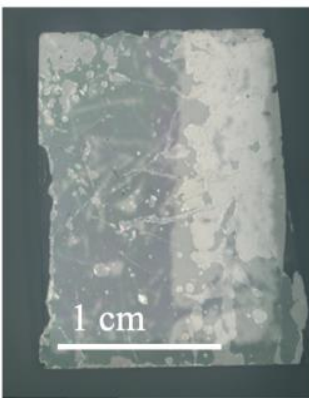

B.

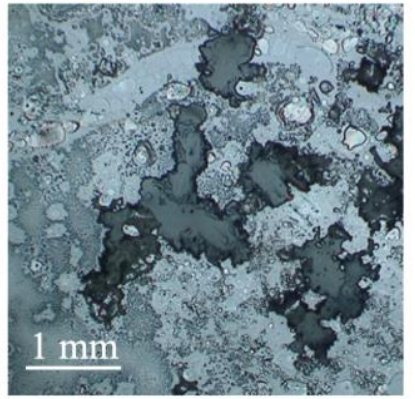

C.

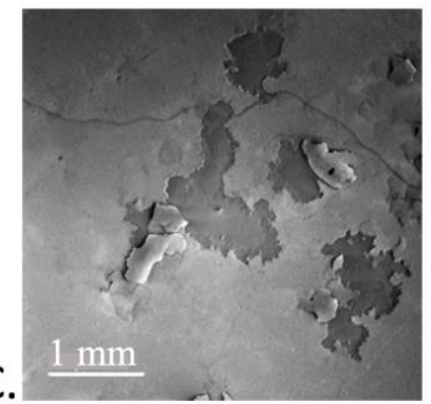

404 Figure 8: Post-accelerated aging (14 days) micrographs of ALD coated glass. (A) Tiled reflected bright-field

405 micrographs of a sample surface that has been coated with $90 \mathrm{~nm} \mathrm{Al} \mathrm{O}_{3} \mathrm{ALD}$, (B) reflected bright-field micrograph of a region showing delamination and the glass substrate on sample that had been coated with $26 \mathrm{~nm}$ of $\mathrm{TiO}_{2} \mathrm{ALD}$, and $(\mathrm{C})$ a secondary electron image of the same delaminated region in (B).

Estimating the Fraction of Exposed Glass Surface

To attempt an understanding of the formation and effect of bare areas on the performance

411 of the ALD films as water permeation barriers it is necessary to begin with a rough assessment of

412 the approximate fraction of the uncoated surface area following aging. An example of an original

413 image and the processed binary image of a sample on which partial delamination of a film during

414 aging has occurred can be seen in Figure 9. The contrast of the thin film and base glass in this

415 case exist in reflected bright field because the optical properties of the film and glass

416 are different in reflectance.

Figure 9: A. Tiled-visible light micrograph-image of a surface of a float glass sample that had been coated with $90 \mathrm{~nm}$ of $\mathrm{Al}_{2} \mathrm{O}_{3} \mathrm{ALD}$ and subsequently exposed to 14 days of accelerated aging and $\mathrm{B}$. the same image after contrast thresholding. The binary image, B, is comprised of white pixels representing remaining ALD coating, and black pixels that represent exposed glass substrate.
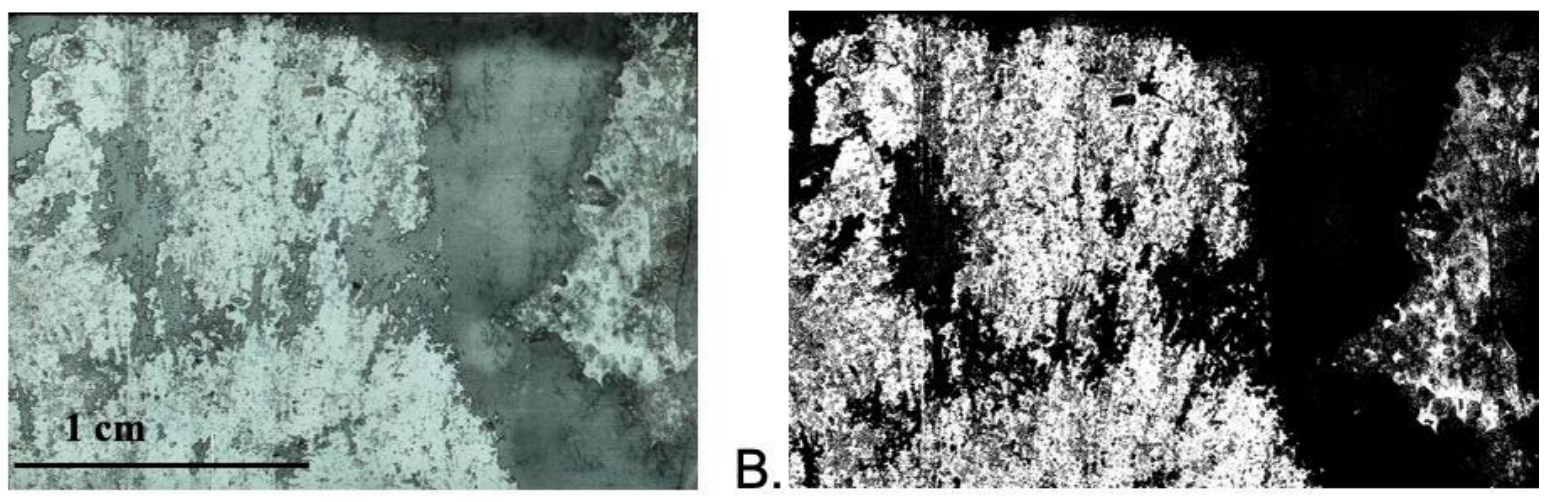
419 presented in Table 5. The measured spatial resolution for this optical microscope and these

420 samples was found to be $\approx 2 \mu \mathrm{m}$. As a result, closely spaced $(\leq 2 \mu \mathrm{m})$ fissures and pinholes were

421 not detectable by this imaging method. Therefore, the values given in Table 4 represent an upper

422 limit on the fraction of the surface still coated. Additionally, this resolution constraint also

423 prevents the detection of any closely spaced defects or pinholes that are present on the surface of

424 the ALD coating prior to aging.

Table 4: Average percentage of coating remaining on the surface of samples of glass coated with a given number of cycles of $\mathrm{Al}_{2} \mathrm{O}_{3} \mathrm{ALD}$ and subjected to accelerated aging at a given temperature for a given length of time. The accelerated aging experiments were run over 14 days unless otherwise indicated. One experiment was run for half that time, as indicated below. Uncertainties were calculated to one standard deviation of the population statistics measured from all samples of each coating type with $n=6$.

\begin{tabular}{ccc}
\hline ALD Method & Cycles & Coating Remaining (\%) \\
\hline $\mathrm{Al}_{2} \mathrm{O}_{3}$ & 500 & $48.5+/-28.0$ \\
$\mathrm{Al}_{2} \mathrm{O}_{3}$ & 1000 & $73.0+/-22.3$ \\
$\mathrm{Al}_{2} \mathrm{O}_{3}$ & 1000 & $95.1+/-6.9$ \\
\hline $\mathrm{TiO}_{2}$ & (following 7 days of aging) & $70.1+/-26.5$ \\
$\mathrm{TiO}_{2}$ & 500 & $89.0+/-8.4$ \\
\hline
\end{tabular}

432 both the $\mathrm{Al}_{2} \mathrm{O}_{3} \mathrm{ALD}$ or $\mathrm{TiO}_{2}$ ALD coated samples. A shorter aging time of 7 days resulted in a

433 much greater percentage of the coating remaining on the sample surface, supporting the model

434 assumption that the bare areas expand as the aging time is increased.

435 The AFM results (Figure 5) indicate that a degree of island coalescence occurs in both of

436 these coatings; however the finite radius of the probe does not allow fissures smaller than $\approx 10$

$437 \mathrm{~nm}$ to be detected, and the presence of such fissures could be the root cause behind this coating

438 loss [31]. In principle the loss could also be due to thermal fracture [37]. Further experiments are 
439 required to distinguish between these and other possibilities to constrain the root cause of coating

440 delamination.

Defects in the ALD Coatings

Defects in ALD coatings have been widely discussed previously in the literature [28, 38,

$44439,40]$ and are important to consider in the context of these experiments. As these coatings are

445 intended to serve as diffusion barriers, slowing the transport of water to the glass surface, the

446 presence of pinholes or fissures through the ALD films would impact the effectiveness of the

447 applied coatings. Fick's first law for diffusion (Equation 1) can be utilized to describe the

448 movement of water through the ALD barrier to the glass surface and to approximate the effect of

449 the presence of such defects [41].

$$
J=-D \frac{d C}{d x}
$$

Equation 1

451 where $J$ is the flux, $D$ is the diffusion coefficient of water or the H-bearing molecular species

452 through the coating, $C$ is its local concentration, and $x$ is the depth beneath the sample surface.

453 This one-dimensional form assumes the ALD coating is uniform and thus defect-free over the

454 entire glass surface. While a defect-free coating is theoretically achievable, [26] in practice,

455 defects are present depending on the condition of the surface to be coated and the growth mode

456 [30]. Extended defects through the amorphous coating can play a similar role to that of grain

457 boundaries or dislocations in a polycrystalline coating; they can provide a more rapid diffusive

458 path for water or other H-bearing molecular species through the coating to the surface

459 underneath. Such an accelerated path results in a change in the apparent (app) diffusivity of

460 water or other hydrogen containing species through the coating $D_{a p p}$ and which can be

461 approximated by using Equation 2: 
464 coefficients for the listed regions. The larger the defect area fraction present in the ALD coating,

465 the greater the contribution of the higher diffusivity $\left(\mathrm{D}_{\text {defect }}\right)$ on the overall apparent diffusion

466 coefficient. Thus, the efficacy of the applied ALD coatings can be directly impacted by the

467 presence of defects in the coating [41].

469 coverage and thermal fracture. Incomplete coverage, either through growth suppression above

470 unfavorable termination sites [39] or locally favorably-terminated sites on an otherwise

471 unfavorably terminated substrate, $[28,29,40]$ can result in pinholes or fissures through the

472 applied ALD coating, respectively. These are illustrated in the schematics in Figure 9.

A.

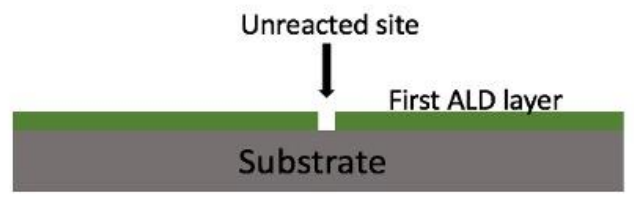

473

474

475

476

477

478 Substrate
Figure 9: Schematic illustrations of
leading to fissure formation) (B).
First ALD layer forms islands Substrate
ure 9: Schematic illustrations of
ding to fissure formation) (B).

B.
Figure 9: Schematic illustrations of pinhole formation by propagation (A) and non-linear deposition (island growth

Pinhole propagates up

through coating

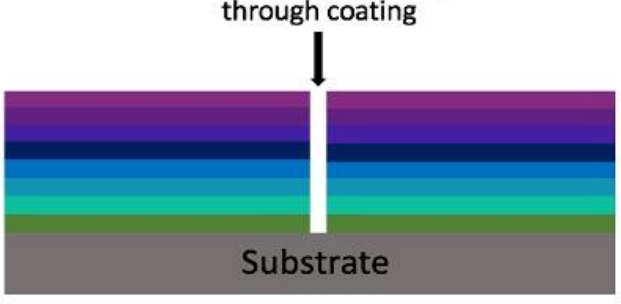

Incomplete coalescence of islands leaves small areas of substrate exposed

Another important mode of defect formation in ALD coatings can be thermal fracture. ALD is typically performed at elevated temperatures $\left(\approx 150^{\circ} \mathrm{C}\right)$ to allow for practical reaction and purge saturation times [27]. Differences in the coefficients of thermal expansion between the 
479 ALD coating and the substrate results in stress as one of these (substrate or coating) contracts

480 more than the other during sample cooling subsequent to deposition. The coefficients of thermal 481 expansion are: $4.2 \times 10^{-6} \mathrm{~K}^{-1}$ for $\mathrm{Al}_{2} \mathrm{O}_{3} \mathrm{ALD}$ [42], $13.9 \times 10^{-6} \mathrm{~K}^{-1}$ for $\mathrm{TiO}_{2} \mathrm{ALD}$ [43], and $8.0 \mathrm{x}$ $48210^{-6} \mathrm{~K}^{-1}$ for commercial float glass $[44,45]$. These differences could result in the blistering $483\left(\mathrm{Al}_{2} \mathrm{O}_{3}\right)$ or fracturing $\left(\mathrm{TiO}_{2}\right)$ of the ALD coatings during cooling to room temperature, provided 484 the thermal stress exceeds a critical value [37]. However, systematic experiments by Jen, et al. 485 [46] showed that the critical compressive stress for crack formation for $\mathrm{Al}_{2} \mathrm{O}_{3}$ films on Teflon 486 FEP substrates saturates with film thickness at a lower limiting value of approximately 1.8 GPa. 487 This exceeds the thermal stress calculated for lowering the temperature from $150^{\circ} \mathrm{C}$ to $25^{\circ} \mathrm{C}$, at $488113 \mathrm{MPa}$, by more than an order of magnitude, and seemingly makes thermal fracture an 489 unlikely source of failure of the ALD films studied here.

\section{Conclusions:}

492 The application of optically transparent $\mathrm{Al}_{2} \mathrm{O}_{3}$ films via atomic layer deposition was 493 shown to dramatically decrease the release of select major elements ( $\mathrm{Si}$ and $\mathrm{Na}$ ) from float glass 494 when immersed in water at elevated temperatures, and it is thus potentially a conservation 495 treatment for glass in museum environments.

496 While the uptake of the elements by other solid phases formed during alteration cannot be 497 excluded, and therefore artificial suppression of those elements in the altering solution, as 498 another possible explanation for these results, such an explanation could be ruled out if the

499 increasing concentration of $\mathrm{Na}$ and $\mathrm{Si}$ in the leachate scales with their depletion in the glass 500 matrix. Experiments to test this are in progress. 
In contrast, application of $\mathrm{TiO}_{2}$ films did not significantly decrease the release of these

502 elements. There are a number of possible reasons for the difference in performance between the

503 two oxide coatings. It could be due to a difference in the rate, or saturation extent of coalescence

504 of islands for the two types of oxides studied here, possibly because of the relative reactivity or

505 sizes of the organometallic precursors used, respectively.

506 Our observations suggest that the limit to the efficacy of $\mathrm{ALD} \mathrm{Al}_{2} \mathrm{O}_{3}$ coatings in

507 mitigating glass alteration is set by delamination of the films when immersed in water; these may

508 be nucleated at existing pinholes and/or fissure defects in applied $\mathrm{ALD} \mathrm{Al}_{2} \mathrm{O}_{3}$ coatings on silicate

509 glass. Further study is needed to test for the presence and role of such defects and what steps

510 might prevent their formation.

511

512 Abbreviations used in text:

513 AFM: atomic force microscopy

514 ALD: atomic layer deposition

515 DI: deionized

516 EDS: energy dispersive spectrometry

517 ICP-MS: inductively coupled plasma mass spectrometry

518 PPM: parts per million (molar)

519 RMS: root-mean-square

520 SEM: secondary electron microscopy

521 TFE: tetrafluoroethylene

522 TDMAT: tetrakis(dimethylamido)titanium

523 TMA: trimethylaluminum 
$524 \mu \mathrm{XRF}$ : micro-xray fluorescence

\section{Declarations:}

527 Disclaimer: Trade names and commercial products are identified in this paper to specify the 528 experimental procedures in adequate detail. This identification does not imply recommendation

529 or endorsement by the authors or by the National Institute of Standards and Technology, nor

530 does it imply that the products identified are necessarily the best available for the purpose.

531 Contributions of the National Institute of Standards and Technology and Museum Conservation

532 Institute (a member of the Smithsonian Institution) are not subject to copyright.

533 Availability of data and materials: The datasets used and/or analyzed during the current study are

534 available from the corresponding author on reasonable request.

535 Competing Interests: The authors declare that they have no competing interests.

$536 \quad$ Funding: Funding for this research came from several sources including a

537 Smithsonian/University of Maryland Seed Grant awarded to RP and EPV and A Big Ten

538 Academic Alliance Smithsonian Fellowship awarded to MEH, in addition to the A. James Clark

539 School of Engineering at the University of Maryland.

540 Author's Contributions:

$541 \mathrm{MH}$ : prepared and ran experiments on the samples studied; performed the majority of the sample

542 analysis; data reduction and analysis; prepared manuscript text.

543 JW: literature review support and guidance in experimental design, results interpretation and

544 manuscript preparation.

545 TL: Assisted with sample analysis via SEM and color measurements. 
NL: Assisted with and provided oversight and guidance for ICP-MS based sample analysis and

547 data reduction.

548 EH: Assisted in sample preparation and analysis.

549 EV: Provided guidance and oversight in experimental design and development; oversaw and

550 participated in SEM based analysis, optical imaging, data interpretation, and manuscript

551 preparation.

552 RP: Oversaw experimental design development, data interpretation, and manuscript preparation.

553 All authors have reviewed and approved of the final version of this: 7/20/2020

554 Acknowledgements

555 The authors would like to acknowledge the contributions to this work made by undergraduate

556 Saeed Bazroon, former Phaneuf Group member Dr. Amy Marquardt, John Abrams and the staff

557 at the Nanofabrication Lab at the University of Maryland and the staff and imaging and analysis

558 facilities at the Smithsonian Institution's Museum Conservation Institute.

\section{$559 \underline{\text { References }}$}

560 [1] Strachan DM, Neeway J. Effects of alteration product precipitation on glass dissolution.

561 Applied Geochemistry [Internet] 2014 June [cited 2020 Feb 10];45: 144-157. Available from:

562 https://www.sciencedirect.com/science/article/abs/pii/S0883292714000675

563 DOI: $10.1016 /$ j.apgeochem.2014.03.013

[2] Zanotto ED, Mauro JC. The glassy state of matter: Its definition and ultimate fate. Journal of 566 Non-Crystalline Solids 471 (2017): 490-495. Available from:

567 https://www.journals.elsevier.com/journal-of-non-crystalline-solids/highlighted-articles/the-

568 glassy-state-of-matter-its-definition-and-ultimate-fate

[3] Gulbiten O, Mauro JC, Guo X, Boratav O. Viscous flow of medieval cathedral glass. Journal

574 [4] Frankel GS, Vienna JD, Lian J, Scully JR, Gin S, Ryan JV, Wang J, Kim SH, Windl W, Du J. 575 A comparative review of the aqueous corrosion of glasses, crystalline ceramics, and metals. NPJ 
Materials Degradation [Internet]. 2018 April [cited 2020 Feb 10]; 2(15):1-17. Available from: https://www.nature.com/articles/s41529-018-0037-2 DOI: $10.1038 / \mathrm{s} 41529-018-0037-2$

[5] Brill RH. Crizzling - a problem in glass conservation. Studies in Conservation [Internet]. 1975 Jul [cited 2020 Feb 10]; 20(1):121-134. Available from: https://www.tandfonline.com/doi/abs/10.1179/sic.1975.s1.021 DOI: $10.1179 /$ sic.1975.s1.021

[6] Vienna J, Kim DS, Skorski D, Matyas J. Glass property models and constraints for estimating the glass to be produced at Hanford by implementing current advanced glass formulation Efforts. PNNL-22631[Internet] 2013 Jul [cited 2020 Feb 10];1. Available from: https://www.osti.gov/biblio/1170502-glass-property-models-constraints-estimating-glassproduced-hanford-implementing-current-advanced-glass-formulation-efforts DOI: $10.2172 / 1170502$

[7] Jantzen CM, Brown KG, Pickett JB. Durable glass for thousands of years. International Journal of Applied Glass Science [Internet] 2010 March [cited 2020 Feb 10]; 1:38-62. Available from: https://ceramics.onlinelibrary.wiley.com/doi/abs/10.1111/j.2041-1294.2010.00007.x DOI: $10.1111 / j .2041-1294.2010 .00007$

[8] Naumann V, Lausch D, Hähnel A, Bauer J, Breitenstein O, Graff A, Werner M, Swatek S, Großer S, Bagdahn J, Hagendorf, C. Explanation of potential-induced degradation of the shunting type by Na decoration of stacking faults in Si solar cells. Solar Energy Materials and Solar Cells [Internet] 2014 January [cited 2020 March 27]; 120(A):383-389. Available from: https://www.sciencedirect.com/science/article/pii/S0927024813003000

[9] Doremus RH. Interdiffusion of hydrogen and alkali ions in a glass surface. Journal of Non Crystalline Solids [Internet]. 1975 Dec [cited 2020 Feb 10];19:137-144. Available from: https://www.sciencedirect.com/science/article/abs/pii/0022309375900794 DOI:10.1016/0022-3093(75)90079-4

[10] Backhouse DJ, Fisher AJ, Neeway, JJ, et al. Corrosion of the International Simple Glass under acidic to hyperalkaline conditions. Mater Degrad [Internet]. 2018 Aug [cited $2020 \mathrm{Feb}$ 10]; 2(29). Available from: https://www.nature.com/articles/s41529-018-0050-5 DOI:10.1038/s41529-018-0050-5

[11] Donatti, Dario A., Alberto Ibañez Ruiz, and Dimas R. Vollet. "A kinetic study of drying of TEOS-derived gels under nearly isothermal conditions." Materials Research 2.1 (1999): 43-47

[12] Frugier P, et al. SON68 nuclear glass dissolution kinetics: current state of knowledge and basis of the new GRAAL model. Journal of Nuclear Materials [Internet]. 2008 Oct [cited 2020 Feb 10];380(1-3):8-21. Available from: https://www.sciencedirect.com/science/article/pii/S0022311508003668 DOI: 10.1016/j.jnucmat.2008.06.044 
622 [13] Hellmann, R, Cotte S, Cadel E, Malladi S, Karlsson LS, Lozano-Perez S, Cabié M, Seyeux

623 A. Nanometre-scale evidence for interfacial dissolution-reprecipitation control of silicate glass

624 corrosion. Nature Materials [Internet]. 2015 Jan [cited 2020 Feb 10]; 14:307-311. Available from: https://www.nature.com/articles/nmat4172\#citeas

DOI: $10.1038 /$ nmat4172

[14] Dal Bianco B. Investigation on sol-gel silica coatings for the protection of ancient glass: interaction with glass surface and protection efficiency. Journal of Non-Crystalline Solids [Internet] 2008 [cited $2020 \mathrm{Feb} 10] ; 354(26): 2983-2992$. Available from: https://www.researchgate.net/publication/239627095_Investigation_on_solgel_silica_coatings_for_the_protection_of_ancient_glass_Interaction_with_glass_surface_and_p rotection_efficiency

DOI: $\underline{0} .1016 / j . j n o n c r y s o l .2007 .12 .004$

[15] Wang B, Cunning B, Park S, Huang M, Kim J, Ruoff R. Graphene coatings as barrier layers to prevent the water-induced corrosion of silicate glass. American Chemical Society Nano [Internet] 2016 Oct [cited 2020 Feb 10]; 10(11):9794-9800. Available from: https://pubs.acs.org/doi/10.1021/acsnano.6b04363

[16] Maekawa S. editor. Oxygen Free Museum Cases. Getty Conservation Institute, Los Angeles. c1998.

[17] Rueden C, Dietz C, Horn M, Schindelin J, Northan B, Berthold M, Eliceiri K. (2016). ImageJ Ops [Software]. https://imagej.net/Ops.

[18] Friel, J. J., R. Terborg, S. Langner, T. Salge, M. Rohde, and J. Berlin. X-Ray and Image Analysis in Electron Microscopy.. Pro Buisness Verlag 3rd ed. c2017.

[19] Vicenzi EP, Eggins S, Logan AL, and Wysoczanski W Microbeam Characterization of Corning Archeological Reference Glasses: New Additions to the Smithsonian Microbeam Standard Collection. Journal Research Natl. Inst. Standards Technol. 2002 Dec. [cited 2020 Feb

\section{DOI: $\underline{10.6028 / \text { jres. } 107.058}$}

[20] Gateau P. Solubility of tin oxide in soda-lime silicate melts. Journal of Non-crystalline Solids [Internet]. 2012 April [cited 2020 Feb 10];358(8):135-1140. Available from: https://www.sciencedirect.com/science/article/abs/pii/S002230931200083X DOI: 10.1016/j.jnoncrysol.2012.02.009

[21] Code of Ethics. American Institute of Conservation. 2019. https://www.culturalheritage.org/about-conservation/code-of-ethics. Accessed 2020 April 8.

[22] Marquardt AE. Novel protective coatings for silver and copper alloy cultural heritage objects using atomic layer deposited metal oxide barrier films. Doctoral Dissertation, University 
666

667

668

669

670

671

672

673

674

675

676

677

678

679

680

681

682

683

684

685

686

687

688

689

690

691

692

693

694

695

696

697

698

699

700

701

702

703

704

705

706

707

708

709

of Maryland College Park. December 2015 [cited 2020 April 24]. Available from:

https://drum.lib.umd.edu/handle/1903/17239

[23] Abdulagatov A, Yan Y, Cooper J, Zhang Y, Gibbs Z, Cavanagh A, Yang R, Lee Y, George $\mathrm{S} \mathrm{Al2O} 3$ and $\mathrm{TiO} 3$ atomic layer deposition on copper for water corrosion resistance, American Chemical Society Applied Material Interfaces [Internet]. 2011 Dec [cited 2020 Feb 10];3(12):4593-601. Available from: https://www.ncbi.nlm.nih.gov/pubmed/22032254 DOI: $10.1021 / \mathrm{am} 2009579$

[24] Haschke M, Boehm S. Advances in Imaging and Electron Physics, Chapter 1: Micro-XRF in Scanning Electron Microscopes, Vol 199, pg 1-60. Elsevier Inc. c2017.

ISN: $1076-5670$

[25] ASTM C1285 - 14. Standard Test Methods for Determining Chemical Durability of Nuclear, Hazardous, and Mixed Waste Glasses and Multiphase Glass Ceramics: The Product Consistency Test (PCT). ASTM International. Accessed 2020 Jan 10.

[26] Puurunen RL. Surface chemistry of atomic layer deposition: A case study for the trimethylaluminum/water process. Journal of applied physics [Internet] 2005 April [cited 2020 Feb 10]; 97(121301). Available from: https://aip.scitation.org/doi/10.1063/1.1940727

[27] George SM. Atomic layer deposition: an overview. Chem Rev [Internet]. 2009 Feb [cited 2020 Feb 10]; 110(1):111-131. Available from: https://pubs.acs.org/doi/10.1021/cr900056b DOI: $10.1021 / \mathrm{cr} 900056 \mathrm{~b}$

[28] Puurunen RL, Vandervorst W, Besling W, Richard O, Bender H, Conard T, Zhao C et al. Island growth in the atomic layer deposition of zirconium oxide and aluminum oxide on hydrogen-terminated silicon: Growth mode modeling and transmission electron microscopy. Journal of applied physics [Internet] 2004 Oct [cited 2020 Feb 10];96(9): 4878-4889. Available from: https://aip.scitation.org/doi/abs/10.1063/1.1787624?journalCode=jap

DOI: $10.1063 / 1.1787624$

[29] McDonnell S, et al. Controlling the atomic layer deposition of titanium dioxide on silicon: dependence on surface termination. The J of Phys Chem C [Internet] 2013 Sept [cited $2020 \mathrm{Feb}$ 10]; 117(39): 20250-20259. Available from https://pubs.acs.org/doi/abs/10.1021/jp4060022 DOI: $10.1021 / \mathrm{jp} 4060022$

[30] Yerzak A, Lee Y. Probabilistic distributions of pinhole defects in atomic layer deposited films on polymeric substrates. Journal of Vacuum Science and Technology A: Vacuum, Surfaces and Films [Internet] 2016 Jan [cited 2020 Feb 10]; 34(1). Available from: h

[31] Westra KL, Thomson DJ. Effect of tip shape on surface roughness measurements from atomic force microscopy images of thin films. Journal of Vacuum Science and Technology B: Microelectronics and Nanometer Structures Processing Measurement and Phenomena. 1995 December [cited 2020 April 14]; 13(2) 344-349. Available from: http://doi.org/10.1116/1.587943 
[32] Feldmann M, Weißmann R. Initial stages of float glass corrosion. Journal of NonCrystalline Solids [Internet] 1997 Sept. [cited 2020 July 1]; 218: 205-209. Available from:

[33] Jantzen CM, Trivelpiece CL, Crawford CL, Pareizs JM, Pickett, JB. Accelerated Leach Testing of Glass (ALTGLASS): II. Mineralization of hydrogels by leachate strong bases. International Journal of Applied Glass Science [Internet] 2017 Feb [cited 2020 March 23];8(1): 84-96. Available from: https://ceramics.onlinelibrary.wiley.com/doi/abs/10.1111/ijag.12264 [34] Sung CJ, Kim H-J, Choi JW, Han YK. Sodium diffusion in $\mathrm{Al}_{2} \mathrm{O}_{3}$ : a distinct perspective compared with lithium ion diffusion. Nano Letters, Oct 2014 [cited 2020 April 30]; 14: 65596563. DOI: $10.1021 / \mathrm{nl} 503169 v$

[35] Moller J, Reiche D, Bobeth M, Pompe W. Observations of boron nitride thin film delamination due to humidity. Surface and Coatings Technology. [Internet] 2002 Feb. [cited 2020 July 1]; 150: 8-14

DOI: $10.1016 / \mathrm{S} 0257-8972(01) 01500-6$

[36] Cardinale GF, Mirkarimi PB, McCarty KF, Klaus EJ, Medlin DL, Clift WM. Effects of ambient conditions on the adhesion of cubic boron nitride films on silicon substrates. Thin Solid Films [Internet] 1994 Dec. [cited 2020 July 1]; 253(1-2): 130-135. Available from:

https://doi.org/10.1016/0040-6090(94)90307-7

[37] Hutchinson JW. Stresses and failure modes in thin films and multilayers. Notes for a DCAMM Course: Technical University of Denmark, Lyngby. October 1996 [cited 2020 Feb 10] Available from: https://www.seas.harvard.edu/hutchinson/papers/462-5.pdf

[38] Carcia PF, Mclean RS, Reilly MH. Ca test of Al2O3 gas diffusion barriers grown by atomic layer deposition on polymers. Applied Physics Letters [Internet]. 2006 May [cited 2020 Feb 10]; 89(031915). Available from:

https://aip.scitation.org/doi/abs/10.1063/1.2221912?journalCode=apl

DOI: $10.1063 / 1.2221912$

[39] Carcia PF, McLean RS, Groner MD, Dameron AA, George SM. Gas diffusion ultrabarriers on polymer substrates using $\mathrm{Al} 2 \mathrm{O} 3$ atomic layer deposition and $\mathrm{SiN}$ plasma-enhanced chemical vapor deposition. Journal of Applied Physics [Internet]. 2009 [cited 2020 Feb 10];106(023533) Available from: https://aip.scitation.org/doi/abs/10.1063/1.3159639?journalCode=jap DOI: $10.1063 / 1.3159639$

[40] Puurunen RL, Vandervorst W. Island growth as a growth mode in atomic layer deposition: A phenomenological model. Journal of Applied Physics [Internet] 2004 Sept [cited 2020 Feb 10]; 96(12): 7686-7695. Available from: https://aip.scitation.org/doi/10.1063/1.1810193 DOI: $10.1063 / 1.1810193$

[41] Porter, D. A., Easterling, K. E. \& Sherif, M. Y. Phase Transformations in Metals and Alloys, $3^{\text {rd }}$ ed. Van Nostrnad Reinhold Co. Ltd, UK, c2009. 
757 [42] Miller D, Foster R, Jen S, Bertrand J, Cunningham S, Morris A, Lee Y, George S, Dunn A. 758 Thermo-mechanical properties of alumina films created using the atomic layer deposition

759 technique. Sensors and Actuators A: Physical [Internet] 2010 Nov [cited 2020 Feb 10];164(1-

760 2):58-67 Available from:

761 https://www.sciencedirect.com/science/article/abs/pii/S0924424710004292

762 DOI: 10.1016/j.sna.2010.09.018

764 [43] Saleem M, Honkanen S, Turunen J. Thermal properties of $\mathrm{TiO}_{2}$ films fabricated by atomic 765 layer deposition, International Symposium on Advanced Materials [Internet] 2013 [cited 2020

766 Feb 10];60(1). Available from: https://iopscience.iop.org/article/10.1088/1757-

767 899X/60/1/012008/meta

[44] Barrett, C, Nix W, Tetelman A. The Principles of Engineering Materials, Englewood Cliffs:

[45] Hidnert P. Thermal expansion of five selected optical glasses. Journal of Research of the National Bureau of Standards [Internet] 1954 June [cited 2020 Feb 10]; 52(6):311-312 . films grown by atomic layer deposition. Journal of Applied Physics [Internet] 2011 April [cited 2020 January 10];109:084305. Available from:

https://aip.scitation.org/doi/abs/10.1063/1.3567912 


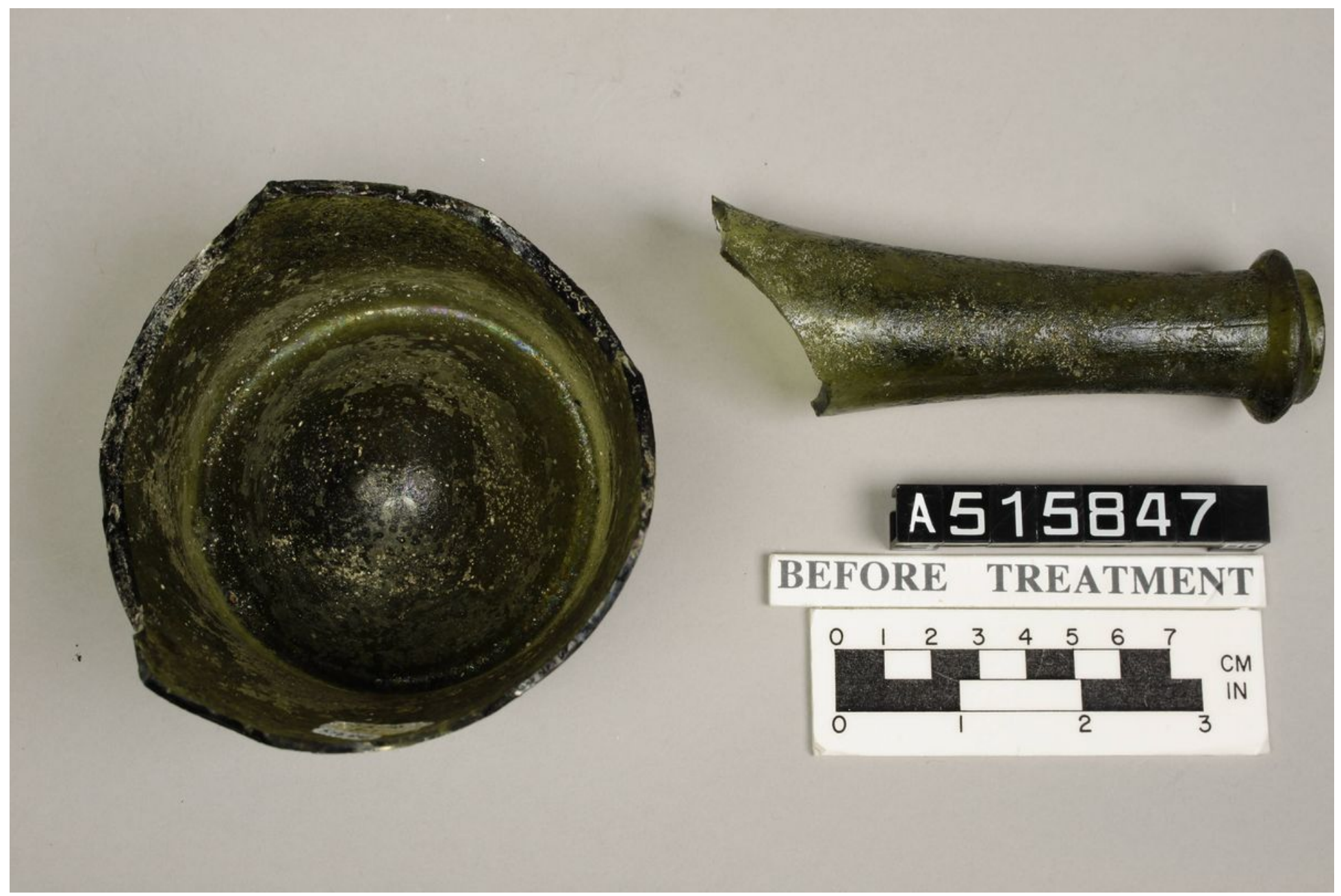

\section{Figure 1}

Fragments of an altered 18th century French glass wine bottle in the collection of the Smithsonian Institution's National Museum of Natural History. Excavated by R.K. Harris at Los Adaes in Natchitoches Parish, Louisiana. Photo taken by Anthropology Conservation Lab, Smithsonian Institution. 


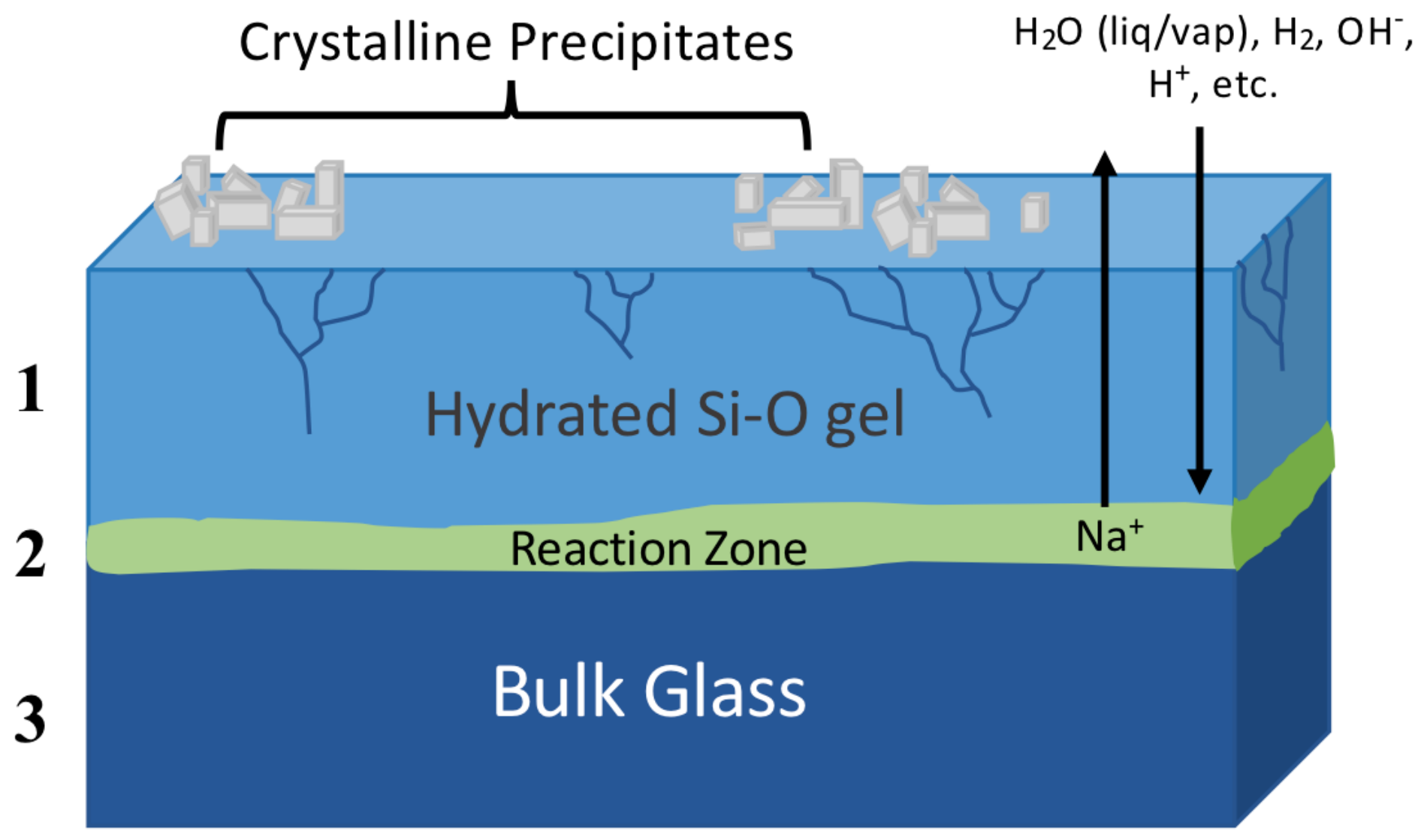

Figure 2

Schematic illustration depicting the three distinct layers of an altered glass surface, assuming a diffusion limited process (adapted from

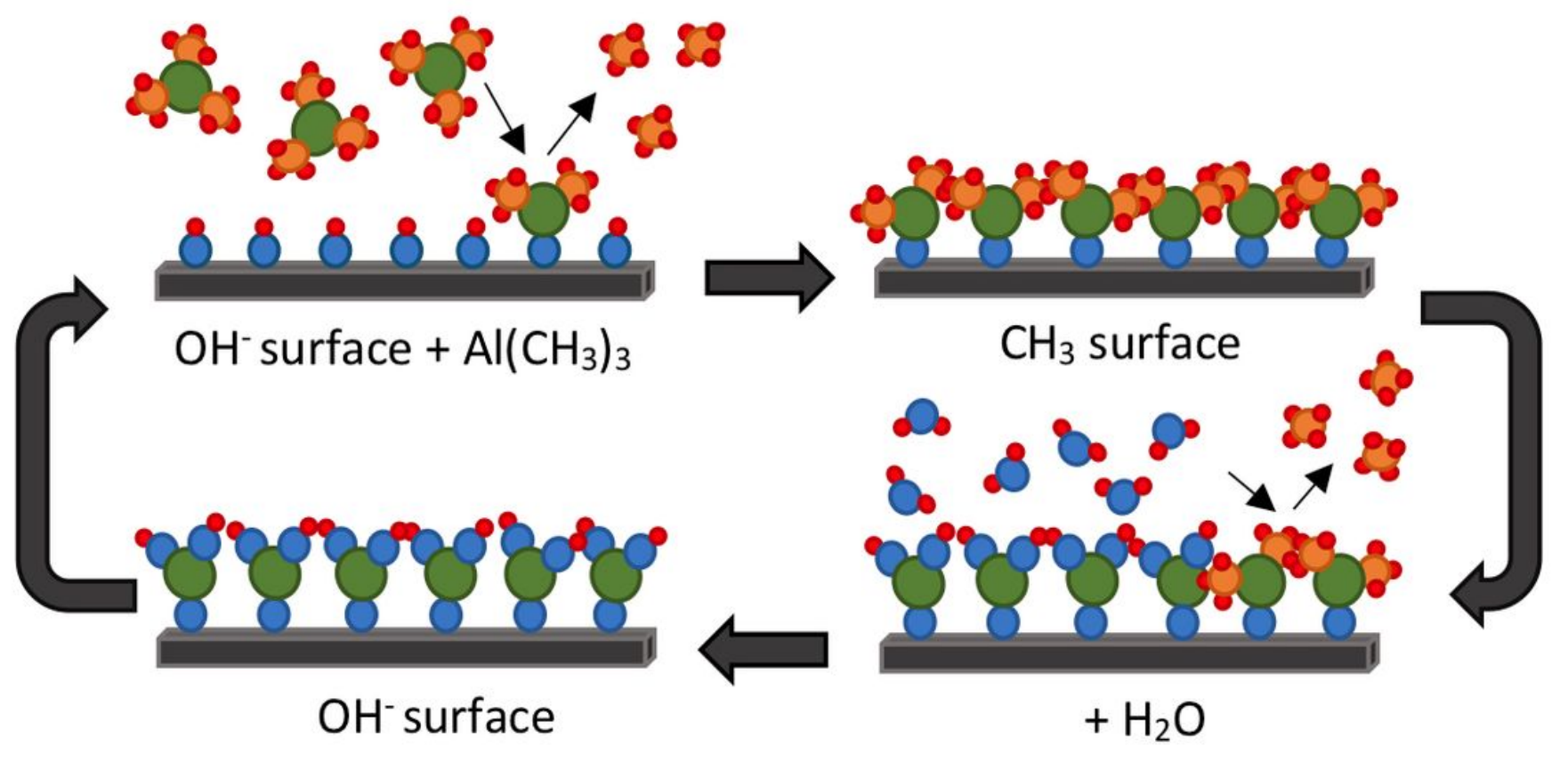




\section{Figure 3}

Schematic of the chemical steps in the idealized depostion of Al203 ALD.

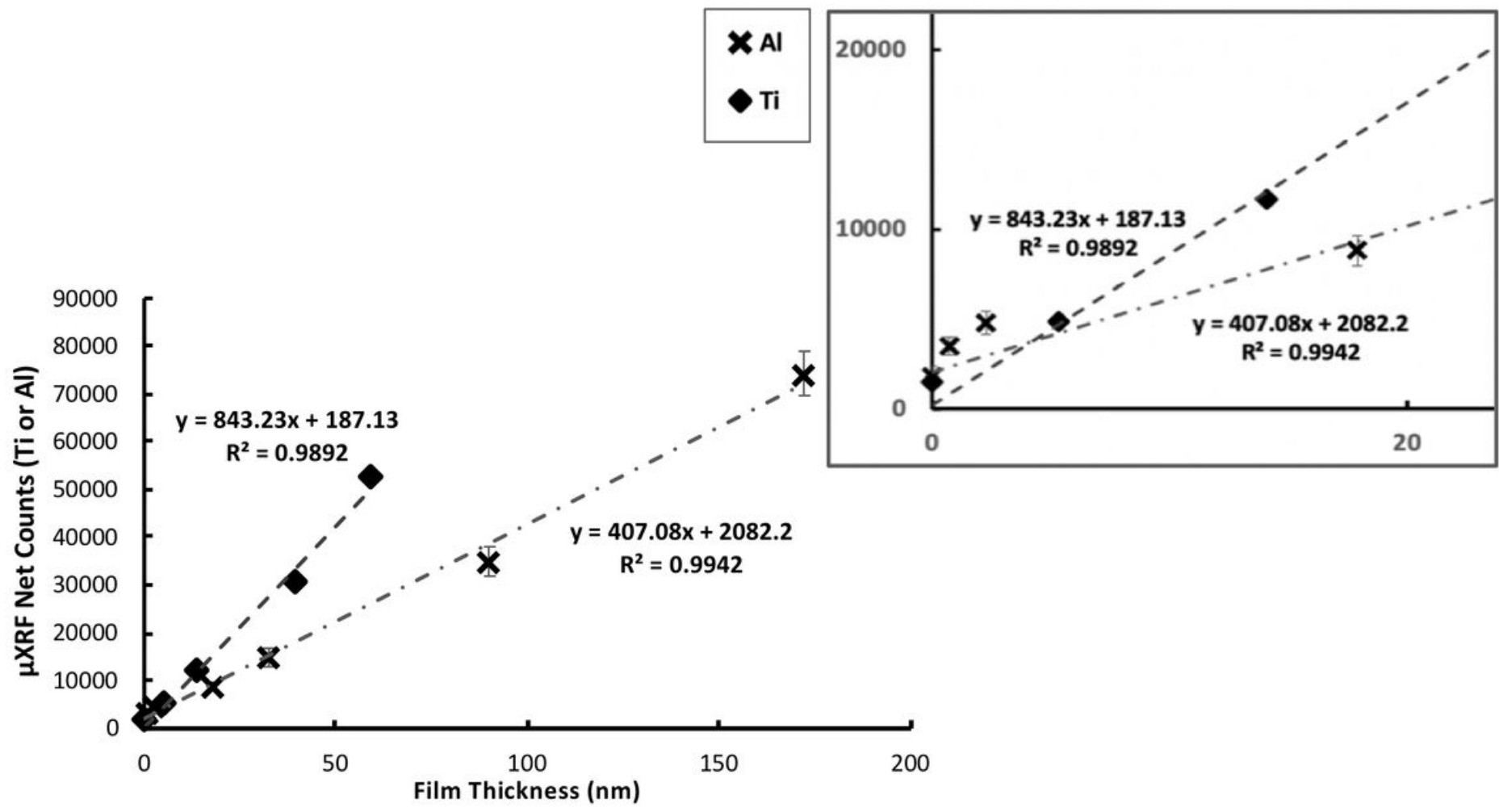

Figure 4

Graph showing relationships between coating thickness values, determined with ellipsometry, and $\mu$ XRF signals. It should be noted that the base glass itself contains small concentrations of both $\mathrm{Al}$ (1833 net counts) and $\mathrm{Ti}$ (1444 net counts), resulting in measured signals from both elements measured on the uncoated glass and accounting for the non-zero y-axis intercepts of the linear regression fits, shown as dashed lines. Error bars represent one standard deviation of the population statistics, however, these values, which are also reported in Table 3, often result in error bars that are too small to be seen in this figure. 

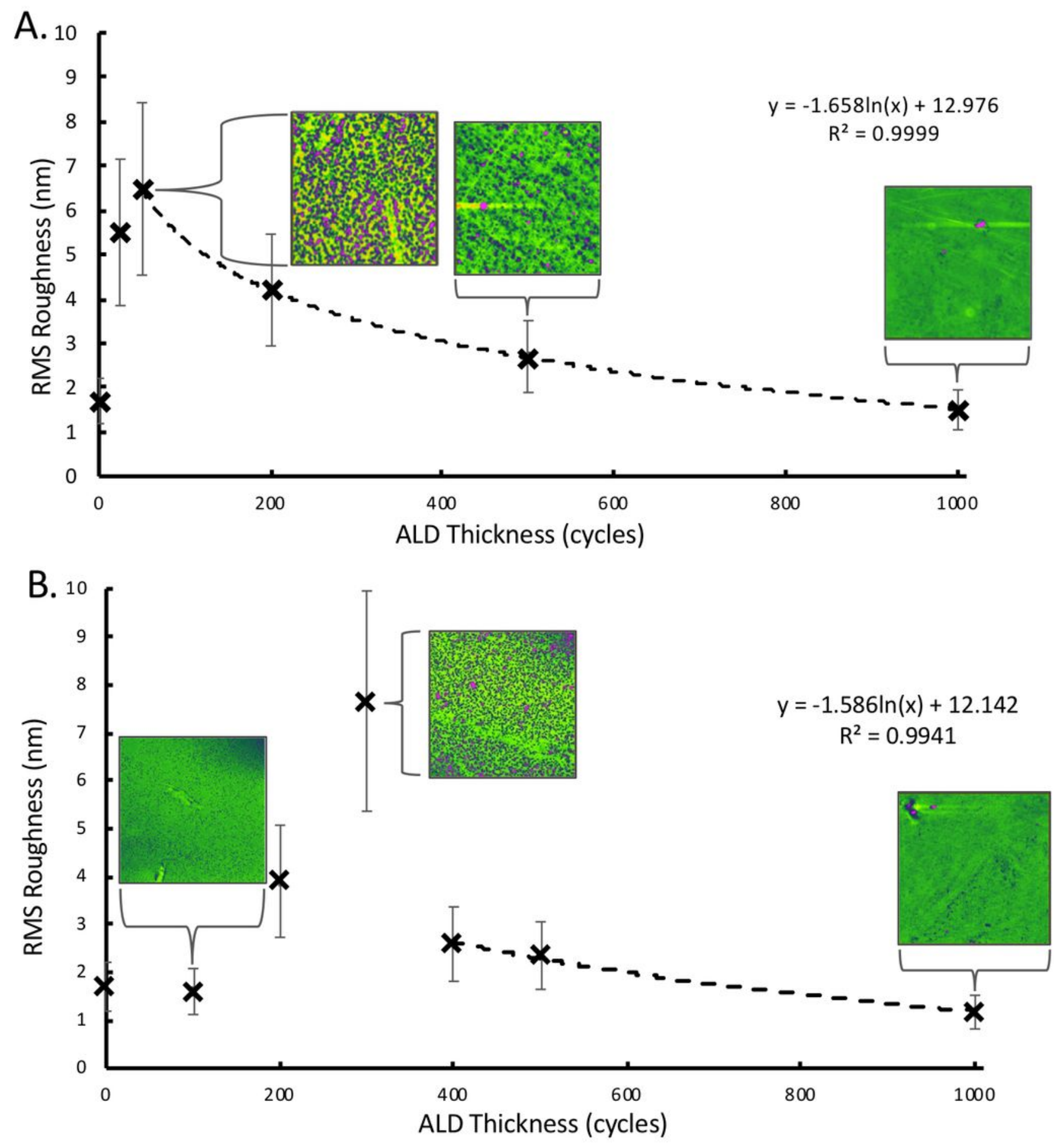

Figure 5

Plots of the average, from multiple measurements across a single surface, RMS roughness measured on samples of float glass with increasing numbers of applied deposition cycles of (A) Al2O3 and (B) TiO2 ALD (in graph B the measurements for doses of 200 cycles, 300 cycles and 400 cycles were obtained at a later time from the rest of the measurements shown). Thumbnail images show AFM topographic maps of selected sample surfaces where the field of view is approximately $10 \square \mathrm{m} \times 10 \square \mathrm{m}$ area (green is 
shallow while purple represents peaks). It has previously been shown that for AFM measurements where the features of interest are at least double the radius of the AFM probe tip, the instrumental uncertainty is estimated to be less than $15 \%$ of the measurement [31]. Uncertainties are reported here to $30 \%$ of the measured value for $n=1$.

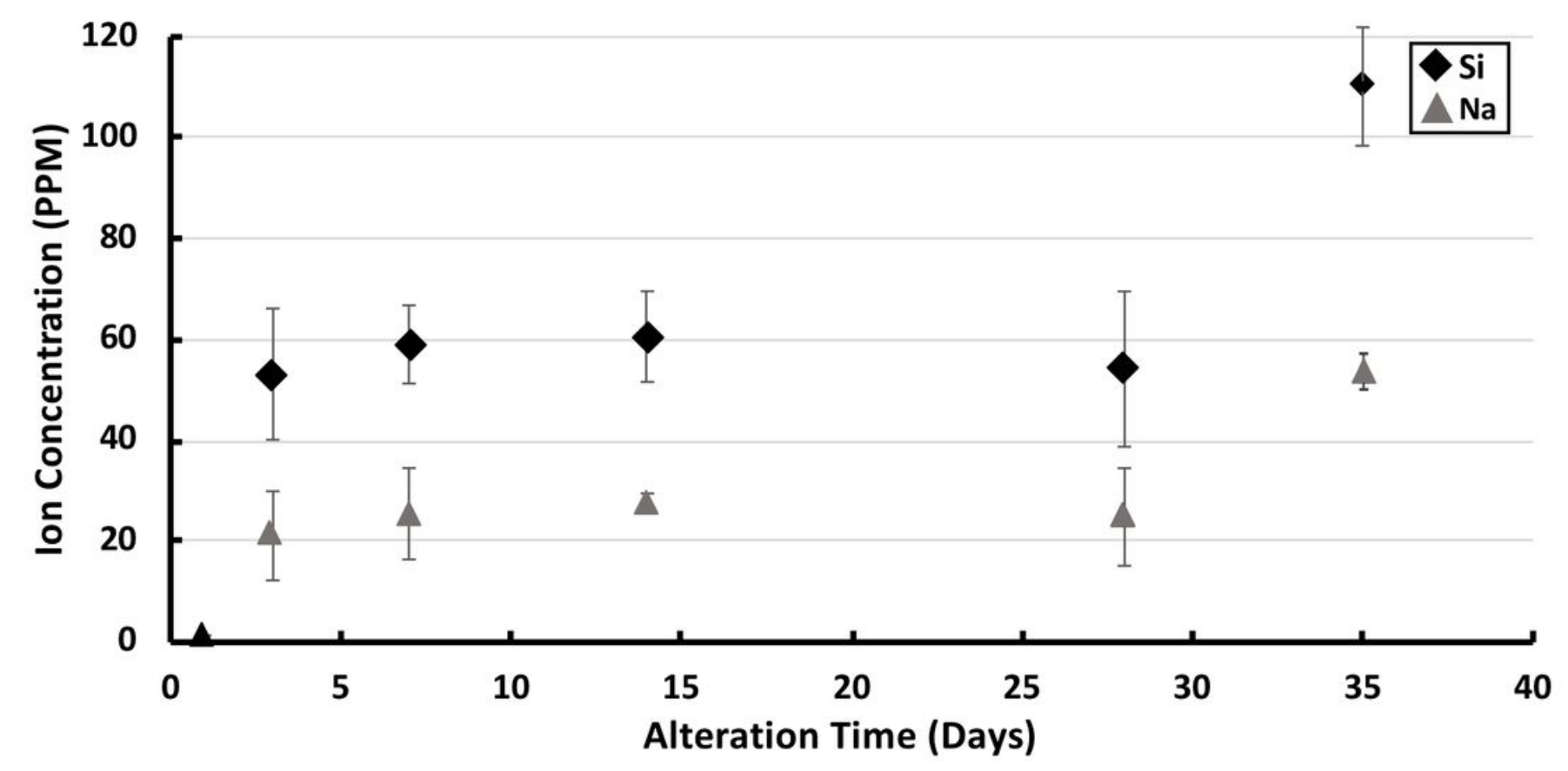

Figure 6

Solution-ICP-MS data showing average concentrations measured for $\mathrm{Si}$ and $\mathrm{Na}$ present in the water used in accelerated aging of uncoated glass samples after increasing accelerated aging time $(n=6$; except for 14 days aging where $n=12$ ). Uncertainties are shown to one standard deviation of the population statistics. 

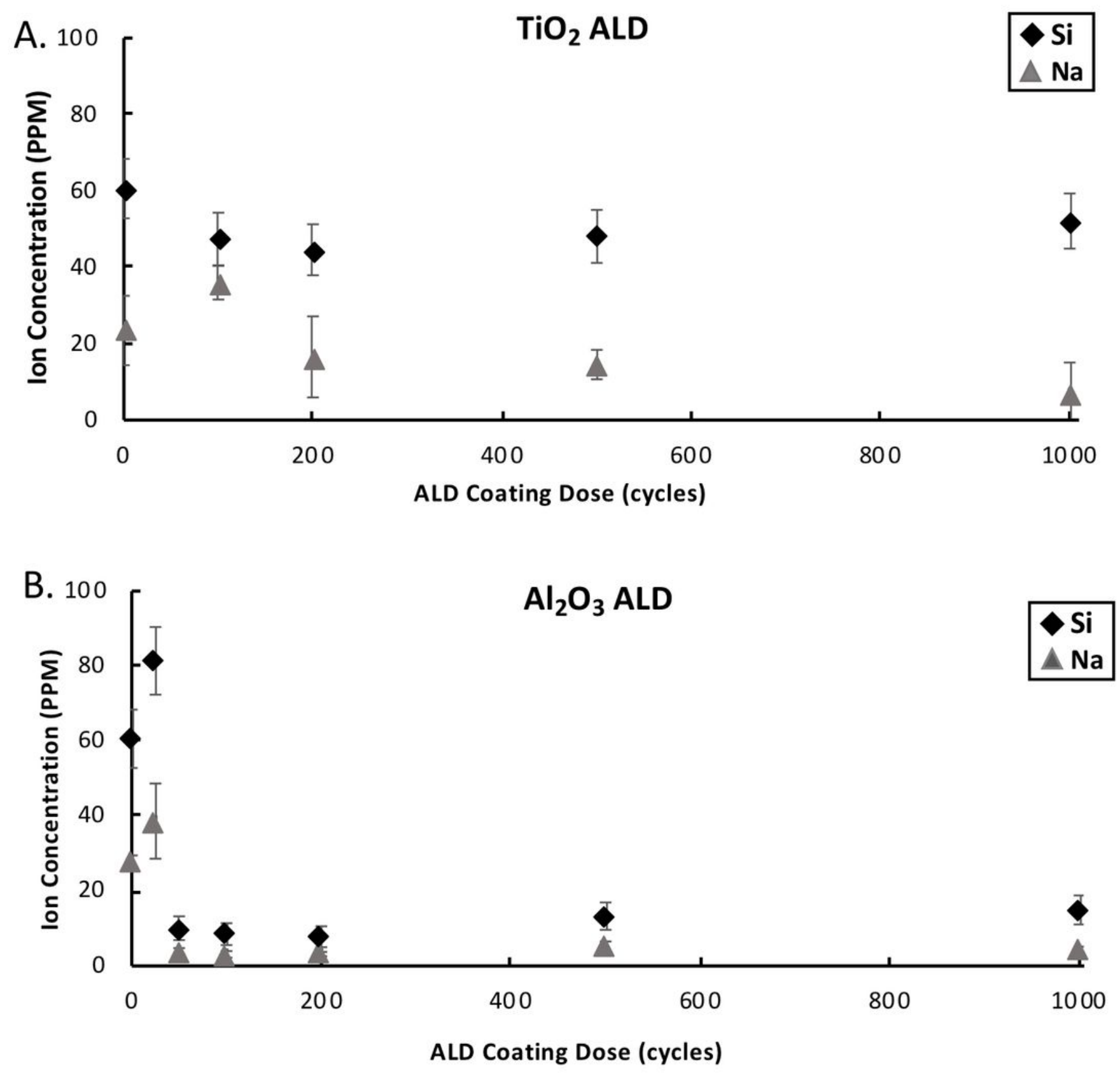

Figure 7

$\mathrm{Si}$ and $\mathrm{Na}$ ion concentration data obtained from the water from the 14 days $+/-4$ hours of accelerated aging of samples of float glass that had been coated with increasing numbers of deposition cycles of $(A)$ TiO2 ALD and (B) Al203 ALD. Points plotted at zero cycles show data obtained from glass samples without any applied coatings (also shown in Figure 6). Multiple samples were aged $(n=6)$ for each coating and relative thickness reported. Uncertainties reported to one standard devation of the population statistics. 

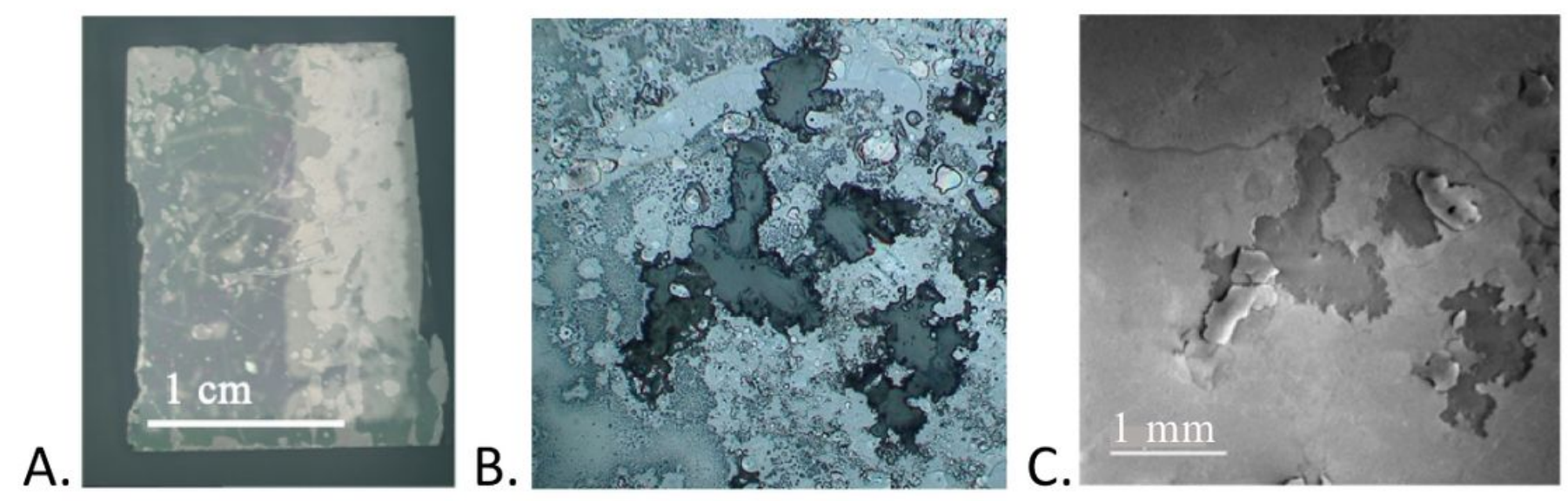

Figure 8

Post-accelerated aging (14 days) micrographs of ALD coated glass. (A) Tiled reflected bright-field micrographs of a sample surface that has been coated with $90 \mathrm{~nm}$ Al2O3 ALD, (B) reflected bright-field micrograph of a region showing delamination and the glass substrate on sample that had been coated with $26 \mathrm{~nm}$ of TiO2 ALD, and (C) a secondary electron image of the same delaminated region in (B).

A.
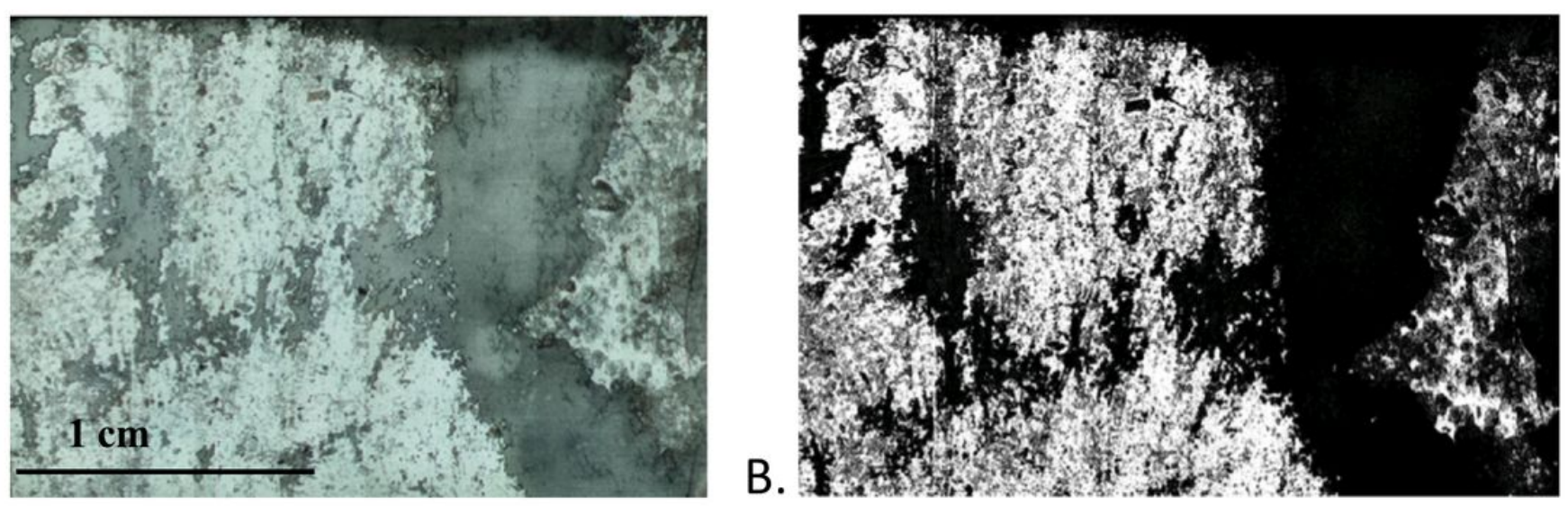

Figure 9

A. Tiled-visible light micrograph-image of a surface of a float glass sample that had been coated with 90 $\mathrm{nm}$ of Al203 ALD and subsequently exposed to 14 days of accelerated aging and $B$. the same image after contrast thresholding. The binary image, $B$, is comprised of white pixels representing remaining ALD coating, and black pixels that represent exposed glass substrate. 
A.
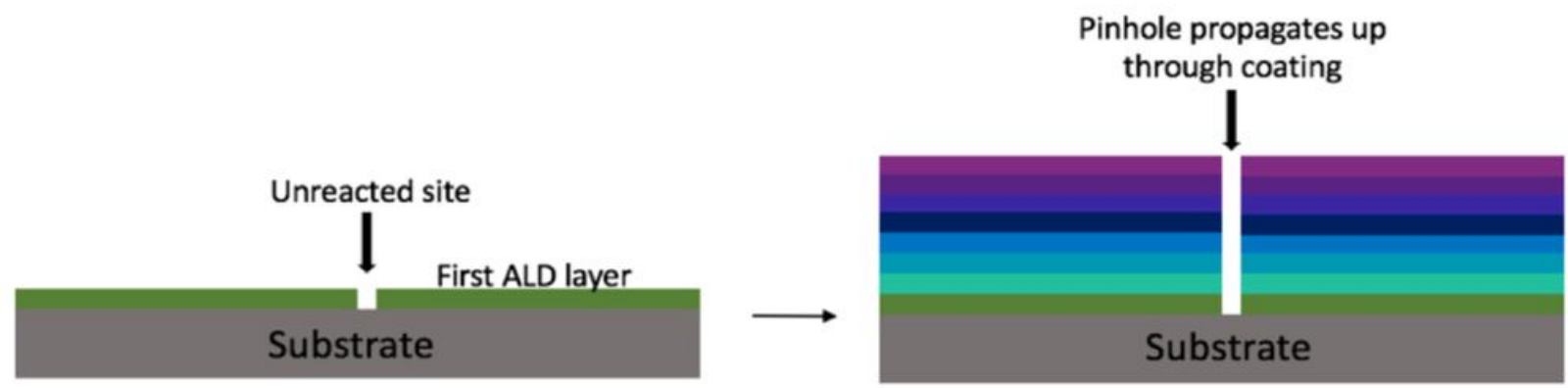

B. First ALD layer forms islands

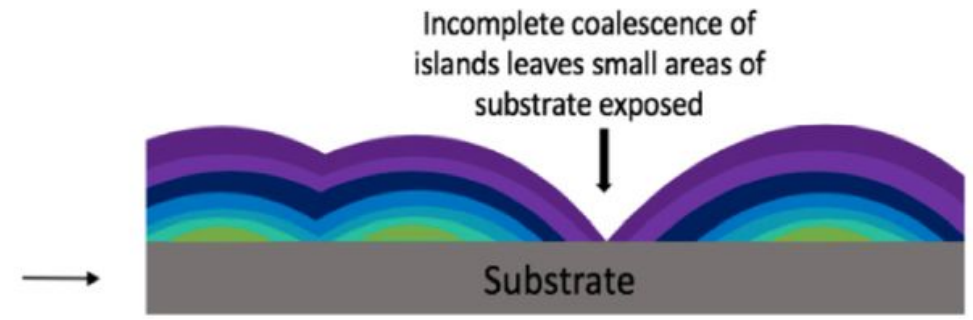

Figure 10

Schematic illustrations of pinhole formation by propagation $(A)$ and non-linear deposition (island growth leading to fissure formation) (B).

\section{Supplementary Files}

This is a list of supplementary files associated with this preprint. Click to download.

- ALDonGlassSI.pdf 